1

\title{
LECITASE ULTRA: A PHOSPHOLIPASE WITH GREAT POTENTIAL IN
}

\section{BIOCATALYSIS}

Jose J. Virgen-Ortíz ${ }^{1}$, José C.S. dos Santos² ${ }^{2}$ Claudia Ortiz ${ }^{3}$, Ángel Berenguer-Murcia ${ }^{4}$, Oveimar Barbosa ${ }^{5}$, Rafael C. Rodrigues ${ }^{6}$, Roberto Fernandez-Lafuente ${ }^{7, *}$

${ }^{1}$ CONACYT - Centro de Investigación en Alimentación y Desarrollo, A.C. (CIAD) Consorcio CIDAM, Km. 8 Antigua Carretera a Pátzcuaro s/n, 58341 Morelia, Michoacán, México.

${ }^{2}$ Instituto de Engenharias e Desenvolvimento Sustentável, Universidade da Integração Internacional da Lusofonia Afro-Brasileira, CEP 62790-970, Redenção, CE, Brazil.

${ }^{3}$ Escuela de Microbiología, Universidad Industrial de Santander, Bucaramanga, Colombia ${ }^{4}$ Instituto Universitario de Materiales, Departamento de Química Inorgánica, Universidad de Alicante, Campus de San Vicente del Raspeig, Ap. 99 - 03080 Alicante, Spain.

${ }^{5}$ Departamento de Química, Facultad de Ciencias. Universidad del Tolima, Ibagué, Colombia.

${ }^{6}$ Biocatalysis and Enzyme Technology Lab, Institute of Food Science and Technology, Federal University of Rio Grande do Sul, Av. Bento Gonçalves, 9500, P.O. Box 15090, Porto Alegre, RS, Brazil.

${ }^{7}$ Departamento de Biocatálisis ICP-CSIC. Campus UAM-CSIC. Cantoblanco. 28049 Madrid. Spain.

* Corresponding author: Prof. Dr. Roberto Fernández-Lafuente. Departamento de Biocatálisis. ICP-CSIC. C/ Marie Curie 2. Campus UAM-CSIC. Cantoblanco. 28049

Madrid, Spain. e-mail: $\underline{\text { rfl@icp.csic.es. }}$ 


\section{Abstract}

Lecitase Ultra is a chimera produced by the fusion of the genes of the lipase from

27 Thermomyces lanuginosus and the phospholipase A1 from Fusarium oxysporum. The

28 enzyme was first designed for the enzymatic degumming of oils, as that problem was not

29 fully resolved before. It is commercialized only as an enzyme solution by Novo Nordisk A/S.

30 This review shows the main uses of this promising enzyme. Starting from the original

31 degumming use, the enzyme has found applications in many other food modification

32 applications, like production of structured phospholipids (e.g., derivatives of

33 phosphatidylcholine), tuning the properties of flour, etc. Moreover, the enzyme has been used

34 in fine chemistry (resolution of racemic mixtures), in the production of aromas and

35 fragrances, polymers modification, etc. Some papers show the use of the enzyme in biodiesel

36 production. Moreover, we present the different technologies applied to obtain a suitable

37 immobilized biocatalyst, remarking the immobilization via interfacial activation and how

38 heterofunctional acyl supports may solve some of the limitations. Immobilized enzyme

39 physical and chemical modifications have also been presented. Finally, Lecitase Ultra has

40 been one of the model enzymes in a new strategy to coimmobilize lipases and other less

41 stable enzymes.

43 Key words: Phospholipase, oil degumming, structured lipids, enzyme immobilization, 44 interfacial activation, enzyme stabilization, enzyme modulation. 


\section{1.- Introduction}

Enzymes are the biocatalysts that perform all metabolic reactions and in vivo

47 biotransformations. They have been submitted to a continuous natural selection throughout an unyielding evolution process to reach the apex as (almost) ideal catalysts for their

49 physiological functions, exhibiting a perfect selectivity, specificity and activity under

50 physiological conditions. These very interesting catalytic features raised the interest of

51 researchers worldwide to use enzymes as industrial biocatalysts [1-3]. This interest has been

52 increased with the new environmental constraints that strive to make chemical processes as

53 "green" as possible [4-7]. Enzymes can be very interesting in this sense, as the conditions

54 are mild (ideally the phase will be aqueous, atmospheric pressure and near room temperature)

55 and the selectivity and specificity may save purification steps and increase the atomic

56 economy of the process [8-13]. However, enzymes did not undergo evolution to come out

57 as industrial catalysts, and some properties, convenient as biological catalysts are inadequate

58 for their industrial application. For example, stability under operational conditions may not

59 be enough in many instances. For example when used versus non-physiological substrates

60 activity, selectivity, or specificity may be far from perfect [14]. That means that enzymes

61 need to be enhanced in many instances to overcome these limitations as industrial catalysts.

62 Nowadays, there are many tools that can permit the improvement of enzyme

63 properties. The development of metagenomics tools [15-20] opens up the opportunity of

64 exploring almost the full biodiversity in the search of enzymes with the suitable properties

65 (e.g., enzymes from extreme environments may have improved stabilities). Directed

66 evolution permits to mimic the work made by Nature, but focusing on the enzyme feature(s)

67 that is/are most relevant for the industrial application and accelerating this evolution to 
months/years [21-25]. Site-directed genetic modifications of the enzymes may be better designed thanks to the improvements in modeling, crystallography, etc. In fact, nowadays it is relatively simple to produce chimeric proteins mixing the gens of two different proteins to get the desired properties of each of the involved proteins [26-28]. Chemical modification of the enzymes may be also used to improve enzyme stability or to modulate their catalytic properties $[29,30]$.

Another limitation of industrial enzymes is their usual water solubility, which can complicate their separation from the reaction medium and reuse. Enzyme immobilization was developed to solve this limitation, producing heterogeneous biocatalysts. However, nowadays the purpose of immobilization goes beyond this goal: immobilization may improve enzyme stability, activity (mainly under harsh conditions), selectivity or specificity, decrease inhibition or increase resistance to deleterious chemicals; even purification of the enzymes can be achieved if an adequate immobilization protocol is designed [31-41].

That way, the incorporation of enzymatic biocatalysis to industrial production is becoming accelerated in the last years and may be expected to become even more relevant in the medium term.

\subsection{Lipases in biocatalysis}

Among the most used enzymes, lipases stand out $[42,43]$. The natural function of lipases is the hydrolysis of triglycerides to free fatty acids and glycerol [44]; however, in vitro lipases have been used in a wide variety of reactions, some related to oil modifications (esterifications [45-51], transesterifications [52-56], acidolysis [57-62], interesterifcations 
90 [63-66]), some far from these substrates (resolution of racemic mixtures, regio or enantio

91 selective reactions) and some have even exhibited a diversity of the so-called promiscuous

92 activities far from their natural function [67-75].

Lipases are interfacial enzymes, able to hydrolyze the drops of substrate (oils are not water soluble) [76]. This is performed because the enzyme is able to become adsorbed on the surface of these drops following the so-called interfacial activation mechanism (Figure 1). Most lipases present their active center isolated from the medium by a polypeptide chain called lid. The internal face of the lid is hydrophobic and interacts with the hydrophobic surroundings of the active center [77-84]. This "closed" form is in equilibrium with an "open" form of the lipase that is the active one, where the lid is shifted and exposes the active center. However, the large hydrophobic pocket is unstable under these conditions and the enzyme is mainly in the closed form in saline aqueous homogenous media [77-84]. In the presence of a hydrophobic surface, like drops of oil, this lipase form may be adsorbed and stabilized, and for this reason they can operate at the interface of the oil drops [77-84]. This tendency to become adsorbed on hydrophobic surfaces is not limited to oil drops, and a lipase molecule may be adsorbed on any hydrophobic surface, including hydrophobic immobilization supports [85-87], hydrophobic proteins [88] or the open form of other lipases [89-91]. In fact, this strategy has become a very popular lipase immobilization protocol [92] (Figure 1).

The popularity of lipases has been promoted by their unusual properties. They are among the enzymes with a wider specificity, accepting many different substrates. This may be caused by the physiological necessity of hydrolyzing tri, di and monoglycerides of very different fatty acids. Moreover, lipases do not require any cofactor. Furthermore, some of 
these enzymes are very stable under a wide range of conditions and reaction media. In fact they have been the pioneer enzymes in neomedia such as ionic liquids, supercritical fluids, etc [93-106]. They are largely widespread in biodiversity, thus Nature offers lipases with very different properties, which has resulted in many lipases being commercially available at very large scale.

\section{2.- Phospholipases}

Phospholipases are a diverse class of hydrolases widespread in nature present in all animals, plants and microorganisms and carry out diverse biological functions such as membrane maintenance and remodeling, regulation of cellular mechanisms and signal transduction, lipid mediators production, and digestion in humans [107]. These enzymes hydrolyze the ester bonds of the phospholipidic components of cell membranes to give simpler lipid products, such as free fatty acids, lyso-phospholipids, di-acylglycerols, choline phosphate and phosphatidates [108]. Phospholipids, being the substrate of phospholipases, consist of a glycerol-3-phosphate esterified at its $s n-1$ and $s n-2$ positions with fatty acids, whereas its phosphoryl group can be esterified with head groups such as choline, serine, ethanolamine, or inositol. Phospholipases are classified according to the position they hydrolyze on the phospholipid backbone in the following types: A1, A2, B, C and D (Figure 2). Phospholipase A1 (PLA1; EC 3.1.1.32) and phospholipase A2 (PLA2; EC 3.1.1.4) cleave the acyl ester bonds at $s n-1$ and $s n-2$ positions of phospholipids, respectively, to produce a free fatty acid and 2-acyl lyso-phospholipid or 1-acyl lyso-phospholipid, respectively, therefore they are acyl hydrolases (EC 3.1.1) [109]. There are phospholipases able to hydrolyze both of the fatty acids esterified at the $s n-1$ or $s n-2$ position of the phospholipid and they are named phospholipases B (PLB; EC 3.1.1.5) [110]. Phospholipase C (PLC; EC 

141 [107].

3.1.4.11) cleaves before the glycerophosphate bond, releasing diacylglycerol and a phosphate-containing head group, whereas phospholipase D (PLD; EC 3.1.4.4) cleaves after the terminal phosphodiesteric bond releasing phosphatidic acid, an important intermediate involved in signal transduction, together with the head group associated at the sn-3 position of phospholipid (Figure 2). Phospholipases C and D are phosphodiesterases (EC 3.1.4.1)

Apart from the crucial biological importance of phospholipases, there is a lot of interest in these enzymes from a pharmaceutical and biotechnological perspective. On the one hand, phospholipases are of great medical and scientific interest because, for example, those from snake venom induce significant pharmacological effects such as inhibition of platelet aggregation, hypotension and antitumor activity [111]. On the other hand, the use of phospholipases in industrial applications is increasing due to the development of molecular techniques for the production of recombinant heterologous proteins and the production of new redesigned enzymes with improved catalytic properties, including chemical modification as a tool to improve their stability $[112,113]$.

Currently, phospholipases are commonly used to produce functional foods like phospholipid derivatives (e.g. phosphatidylserine) [114], to reduce the cholesterol content of food, and to refine certain vegetable oils, particularly in terms of oil degumming [115]. Another application is in wheat-based food systems by the production of emulsifier-like molecules such as lyso-phospholipids and monoglycerides by the action of phospholipases on the phospholipids already present in the ingredients (wheat flour, margarine and eggs) [116]. During the industrial processing of starch to produce glucose syrup, a phospholipase is used for removing unwanted lipid contaminants such as lyso-phosphatidylcholine and avoiding clogging of filters [108]. In dairy industry, phospholipases have been introduced as 
a potential processing aid in cheese making, and a significant increase of cheese yield has been obtained; in this case, phospholipases release lyso-phospholipids having better emulsifying properties and favoring fat retention in the final product [117]. Phospholipases also have impact on human nutrition through the development of novel foods or ingredients with enhanced bioactivities and health effects [118].

\section{3.- Lecitase Ultra}

Lecitase Ultra is an example of the commercial success of a chimeric enzyme obtained via a genetic pathway. Novo Nordisk A/S commercialized the phospholipase A1 from Fusarium oxysporum, as Lecitase $®$ Novo for oil degumming. This enzyme attacked the phosphatides contained in the oil phase, and was able to fully hydrolyze them to lysophosphatides, that migrated to the aqueous phase. The result was adequate, but the enzyme stability was not satisfactory for some applications. To solve this problem, the company fused the genes of the lipase from Thermomyces lanuginosus and the phospholipase A1 from Fusarium oxysporum, producing a chimeric enzyme that they named Lecitase Ultra. This way, they combined the stability of the lipase to the A1 phospholipase activity. The enzyme was first reported in 1998 [119], and since them its use has been growing in different areas, far from the initial oil degumming application. The enzyme structure has not been described to date, and only in 2016 its sequence and the amino acid residues involved in the catalytic activity were described [120]. As expected, the results concluded that most of the Lecitase Ultra sequence fits with one or the other parent enzymes. Specifically, sequence 1284 corresponds to the lipase from $T$. lanuginosus and sequence $285-339$, corresponds to the 
182 phospholipase from $F$. oxysporum. The authors also identified the classical "Ser-His-Asp" 183 triplet responsible for enzyme activity [120].

184 Using the search term "Lecitase Ultra" in "all areas" of Scopus, 280 entries may be 185 found (access data 21 January 2019), being the first one dated in 2005 and reaching over 30 186 entries/year in the last 3 years. The uses of this enzyme have never been subject of a review 187 paper, and due to its clearly growing interest, we have felt that it may be interesting to offer 188 a review paper on this commercially available enzyme.

Curiously, this enzyme is supplied only as free enzyme, while most of the lipases may 190 be acquired in free or immobilized forms (e.g., lipase B from Candida antarctica is supplied as Novozym 435, Lipase from Thermomyces lanuginosus as Lipozyme TL IM or from Rhizomucor miehei like Lipozyme RM IM).

\section{Applications of the free Lecitase Ultra.}

197 the uses of these immobilized biocatalysts.

\subsection{Use of Lecitase Ultra in food technology} enzyme. 


\subsubsection{Oil degumming}

Oil degumming, that is, elimination of phosphatides from oil, was traditionally performed by chemical processes, although the water degumming process may be described as a physical process since it does not involve any chemical reaction [121]. Degummed oil improves physical refining, reduces water consumption, the production of wastewater and the energy requirement, moreover, it may increase the yield of refined oil [121]. The employment of enzymes to remove gums from edible fats and oils started in 1992, using Lurgi's EnzyMax® process, that involved a porcine phospholipase A2 [122]. The results were unsatisfactory, and new enzymes were analyzed. Thus, Lecitase Ultra was initially designed to catalyze the degumming of oils and is very used in vegetable oils degumming with very good results [123].

The specificity of Lecitase Ultra versus different kinds of phospholipids was studied using monolayer technology [124]. The pressure of the monolayer film greatly affects the activity of the enzyme. No activity was found for sphingomyelin, while for all other phosphpolipids assayed the specificity was determined ( L- $\alpha$-phosphatidylethanolamine > cardiolipin L > 1,2-diacyl-sn-glycero-3-phospho-L-serine > L- $\alpha$-phosphatidylinositol > 1,2-dioleoyl-sn-glycero-3-phosphocholine) [124].

Lecitase Ultra was applied in degumming of several vegetable oils; the study suggested that over $40{ }^{\circ} \mathrm{C}$ the lipase activity decreased, making predominant the phospholipase activity [125]. In another study, Lecitase Ultra was used in the degumming of different crude rice bran oil, reducing the phosphorous content almost by 50 fold after $2 \mathrm{~h}$ of reaction in the oil phase [126]. In another research, the effect of the enzymatic degumming catalyzed by LysoMax® Oil and Lecitase® Ultra on the crude sunflower oil properties was 
analyzed [127]. Results showed a drastic reduction of phospholipids, but also calcium and

227 magnesium content was reduced, the oxidative stability index was decreased. In another

228 example, soybean and rapeseed oils were degummed by Lecitase Ultra, and a high

229 degumming can be achieved in a short time but the full phospholipids hydrolysis requires

230 longer times [128]. This paper shows that Lecitase Ultra® hydrolyzed $80 \%$ of phosphatidyl

231 ethanolamine after 60 min while only $40 \%$ of phosphatidyl inositol was consumed. Crude

232 sunflower lecithin was treated with Lecitase® Ultra the enzyme hydrolyzed also non-polar

233 lipids and in the used conditions acyl migration permitted full hydrolysis (aqueous system, T

$\left.234=50{ }^{\circ} \mathrm{C}, \mathrm{pH}=5\right)$ [129]. Controlling the hydrolysis process and the presence of 235 lysophospholipids and/or phospholipids, the emulsifying/stabilizing features of the oil could 236 be modulated.

\subsubsection{Modification of choline derivatives}

This is perhaps one of the most specific and interesting uses of Lecitase Ultra, and

was accomplished by diverse reactions.

l- $\alpha$-glycerylphosphorylcholine was produced by Lecitase Ultra catalyzed

242 hydrolysis of soy phosphatidylcholine [130]. The reaction medium was a biphasic

243 water/hexane system, after optimization a purity of $99.3 \mathrm{~g} / 100$ was achieved (after extracting

244 the products with diethyl ether and using a chromatographic step with a silica column).

245 Phosphatidylcholine of soy lecithin was used in the production of L- $\alpha$ -

246 glycerylphosphorylcholine in aqueous medium using Lecitase Ultra as catalyst (94.5\% yield)

247 [131]. The hydrolysis of phosphatidylcholine by Lecitase Ultra in aqueous systems was

248 studied in another paper, determining the thermodynamic constants (activation energy was

$2495.96 \mathrm{~kJ} / \mathrm{mol}$ ) and kinetic constants [132]. Soy phosphatidylcholine was hydrolyzed in hexane 
to produce lysophosphatidylcholine, after optimizing (with a yield of $83.7 \mathrm{~mol} \%$ ) [133]. The

251 product had a content of unsaturated fatty acid that was higher than that of the initial 252 substrate, it was mainly due to linoleic acid.

253 In another research, soybean phosphatidylcholine ethanolysis catalyzed by Lecitase 254 Ultra was used to produce lysophosphatidylcholine with a conversion ratio of $98.3 \%$ after 255 enzyme optimization had been described [134].

256

\subsubsection{Diglycerides production}

Another use of Lecitase ultra, quite far from the degumming, and more similar to uses 259 of a conventional lipase $[135,136]$, is in the production of diglycerides by diverse strategies, 260 including esterification, alcoholysis or partial hydrolysis.

For example, palm oil was hydrolyzed using four commercial lipases (Lipase A,

262 Lipase AY, Lipozyme RM IM and Lipozyme TL IM) and Lecitase Ultra [137]. Lecitase Ultra 263 and Lipozyme RM IM were the most selective enzymes towards hydrolysis of saturated fatty 264 acids, Lecitase Ultra have the highest yields in free fatty acids (94.5\%) [137]. Soybean oil 265 was partially hydrolyzed by Lecitase Ultra with the objective of producing diacylglycerols, 266 with the help of molecular distillation after hydrolysis reaction [138]. Molecular distillation 267 promoted acyl migration in the diglycerides. The hydrolysis of soybean oil catalyzed by 268 Lecitase Ultra in a solvent free system was also performed [139]. Diacylglycerol-enriched 269 palm olein and soybean oil were obtained by a partial hydrolysis catalyzed by Lecitase Ultra 270 in aqueous/oil suspension or solvent free media [140-142] Later, after product purification 271 by molecular distillation, the oxidative stabilities of the product were analyzed [143]. 
In another study, palm oil was submitted to glycerolysis in a solvent-free system to

273 produce diacylglycerol [144]. After optimization, the final content of diacylglycerides was

$27459.5 \%$ in the lipid layer was achieved.

275 Diacylglycerol-enriched oil synthesis was catalyzed by Lecitase Ultra using via 276 esterification of free fatty acids and glycerol (a yield of 42.7 and a purity of $83.1 \%$ were 277 obtained) [145]. In another paper, oleic acid and glycerol were esterified in a reaction

278

279 280

281

283

284

285

286

287

288

289

290

291 catalyzed by Lecitase Ultra in solvent free medium [146]. An esterification efficiency higher than $80 \%$ and a production of almost $55 \%$ of diacylglycerides was found in the lipid layer

\subsection{4.-Modification of flour in bread making}

Surfactants may form amylose-lipid inclusion complexes that reduced bread crumb firming. Considering that free fatty acids or lysolipids are detergent-like molecules, the treatment of the wheat endogenous lipids with enzymes may have some positive effects.

Model gluten-starch were produced in laboratory (resembling flour), and it was found that the blends adsorbed more oil when treated with Lecitase Ultra, showing that the features of this model may be tuned by this treatment [147]. Treatment of wheat flour with Lecitase Ultra had low or even a negative impact on gluten agglomeration and yield, while Lipolase treatment permitted an improvement on the glutted agglomeration [148]. Lipopan F, Lecitase Ultra, and Lipolase treatment of the whet permitted to reduce stiffness intensification, crumb firmness and the decrease in resilience [149]. Lecitase Ultra was compared to Lipopan F in their ability to alter the wheat lipids and how the lipid modification alter the gluten network strength and direct gas cell stabilization, while keeping the dough extensibility unaltered [150]. Amylose-lipid inclusion complexes reduce the access of water molecules to starch granules by forming a lipophilic shield, which increased the rigidity of the starch granule 
296 [151]. The high content of phospholipids contained in wheat germ oil was reduced using

297 Lecitase Ultra and Lysomax, being Lecitase Ultra the most effective (over 85\% phospholipid

298 removal) [152]. The wheat flour lipid composition during bread making was altered

299 employing Lipopan F and Lecitase Ultra to increase the loaf volume [153]. This was related

300 to the decrease of phospholipids and galactolipids and the increase in free fatty acids and

301 lysolipids.

302

303

\subsubsection{Other uses of Lecitase Ultra in food.}

304

Lecitase has many other uses. For example, the acidity of mammalian fats was

reduced to check its carbon and water footprint using as biocatalysts Novozym 435,

Lipozyme IM TL and Lecitase Ultra for mammalian fat [154]. Unfortunately results were uneconomical with the three biocatalysts.

In another case, by combining the hydrolysis catalyzed by Lecitase ${ }^{\circledR}$ Ultra and reversed-phase liquid chromatography with electrospray ionization and sequential mass spectrometry, the regiochemistry of sulfoquinovosylmonoglycerides and

311 sulfoquinovosyldiglycerides in the lipid contained in spinach (Spinacia oleracea) and parsley

312 (Petroselinum crispum) was investigated and the main components determined [155].

313 Another application was in the extraction of proteins from some wastes. The use of Palatase

$31420000 \mathrm{~L}$ and Lecitase Ultra was found to be the best treatment for the extraction of proteins

315 from olive pulp and stone, respectively [156].

Foaming properties of whey protein concentrated solutions were tuned by

317 hydrolysis using Lecitase 10L, Lecitase Ultra and a lyso-phospholipase A2 from Aspergillus 318 niger [157], all biocatalysts permitted to alter this properties. 


\subsection{Use of Lecitase Ultra in chemistry}

Lipases have found many applications in chemical areas, thanks to their broad

322 specificity in many instances coupled to a high enantio and/or region specificity and

323 selectivity $[10,158,159]$. Lecitase Ultra has been employed in most applications described

324 for lipases, although with a lower intensity perhaps due to its name as phospholipase.

For example, one of the most popular uses of lipases is in the production of low

326 chain esters ( flavors and fragrances), because when produced using biocatalysis may be

327 labeled as natural products [160]. For example, Lecitase Ultra has been employed in a direct

328 esterification reaction in the production of methyl benzoate and methyl butanoate in a

329 continuous flow microreactor (with conversions of 54 and $41 \%$, respectively) [161].

330 Resolution of racemic mixtures (exploiting enzyme enantiospecificity) is another

331 very popular use of lipases [162]. Using Lecitase Ultra, the kinetic hydrolytic resolution of

332 different derivatives of (E)-4-phenylbut-3-en-3-ol (acetate or propionate) (4b) catalyzed by

333 Lecitase Ultra yielded (+)-(R)-alcohol and unreacted (-)-(S)-ester (using the propionate ester

334 the enantiospecificity was higher, enantiomeric excesses ranging from 93-99\% [163]. Esters

335 of L amino acids with aliphatic residues are hydrolyzed by Lecitase Ultra with high

336 enantiospecificity while if the side chain is an aromatic ring or $\alpha$-hydroxy acids, the

337 enantiospecificity greatly decreased [145].

Polymer modification and synthesis is another interesting use of lipases [164,165],

339 and Lecitase Ultra has been also employed for this goal. For example, using ultrasounds,

340 Lecitase Ultra was used in the synthesis of poly-4-hydroxybutyrate-co-6- hydroxyhexanoate

341 [166], but the reaction rates were lower than using other biocatalysts although the results

342 were better than using the lipase from Candida rugosa. The effect of the organic solvent in 
343 the modification of poly-3-hydroxyalkanoates by glucose via esterification catalyzed by 344 Lecitase Ultra was studied [167]. Using dimethyl sulfoxide and chloroform the results 345 reached maximum polymer modification (just under 40\%). In another paper, polylactic acid 346 polymers have been synthetized using Lecitase Ultra and Lipozyme TL IM, producing low 347 molecular weight polylactic acid polymers [168]. The polymers were slightly larger using 348 Lecitase Ultra.

\section{3.- Lecitase Ultra in production of biodiesel}

Biodiesel production is one of the most interesting uses of lipases $[169,170]$.

352 However, in many instances this is performed using immobilized enzymes $[171,172]$. We

353 have been able to find just two reports using free Lecitase Ultra in biodiesel production, and

354 they are not directly related to biodiesel production, but in the previous refining to make a 355 specific oil usable to this goal.

The first example is in the use of the oil from Jatropha curcas seeds to produce

357 biodiesel $[173,174]$. However, the presence of a high content of phospholipids in the oil from 358 Jatropha curcas seeds complicates its use in biodiesel; a previous refining process is thus 359 required. LysoMax and Lecitase Ultra were successfully used for degumming of this oil, 360 being more effective Lecitase Ultra, and permitting the use of the final product in the 361 biodiesel production [175].

In the second example, Lecitase Ultra was combined to lipase NS81006 to produce 363 biodiesel from low quality oil, because these oils contain a great percentage of phospholipids 364 [176]. The process was a two-step method. First, the phospholipids were hydrolyzed by 
Lecitase Ultra; later the lipase was used to produce the methyl esters. This permitted to increase the yield from just over $76 \%$ to more than $96 \%$ [176].

\section{Preparation of immobilized biocatalysts of Lecitase Ultra}

As Lecitase Ultra is only supplied as an enzyme solution, the enzyme has been subject of many attempts to prepare a suitable immobilized biocatalysts. As stated previously, a properly immobilized enzyme derivative, together with having a simpler separation from the reaction media, may have many properties improved when compared to the free counterpart, like stability, activity, selectivity, etc. [31-41]. In fact, even when the supplier recommends the use of the enzyme as a free enzyme, immobilization may have significant positive effects on its performance, as it is the case of Eversa lipase [177]. Thus, many research papers pursue the preparation of immobilized biocatalysts from Lecitase Ultra.

\subsection{Lecitase immobilization}

The enzyme has been immobilized on many different supports. For example, it has been immobilized in several instances via ion exchange. In a first example, Lecitase Ultra has been immobilized on aminated bacterial cellulose beads (via ion exchange), that had been coupled to superparamagnetic molecules to have a biocatalyst with response towards a magnet [178]. Immobilization yield of the enzyme was 70\%, without altering their properties. In another example, Lecitase Ultra was immobilized on the commercial support epoxyDILBEAD-VWR [179]. The support was previously modified with polyethylenimine and 
crosslinked with glutaraldehyde, and the enzyme was immobilized via ion exchange. The support can be reused after enzyme inactivation by enzyme release and new loading of fresh enzyme. However, the authors did not investigate in deep if all enzyme molecules were desorbed [179]. Lecitase Ultra immobilized on polyethylenimine/glutaraldehyde DILBEADVWR was used in the resolution of methyl trans-( \pm )-3-(4-methoxyphenyl) glycidate [179]. The reaction was performed in xylene with excellent results (e.e. >99 \%, conversion $50 \%$ ). Lecitase Ultra immobilized on an anionic exchanger greatly increased its activity when adding organic cosolvents or surfactants to the reaction medium (e.g., 12 folds in presence of $15 \%$ ethanol) [180]. The hydrolysis of sardine oil was also improved by these components of the reaction medium, altering the selectivity by eicosipentaenic acid or docosahexaenic acid.

The acidolysis between lecithin and capric acid was catalyzed by Lecitase Ultra ionically exchanged on Amberlite XAD 7HP, and compared to the results using other lipases [181]. The highest molar incorporation value of caprilic acid was obtained using Lecitase Ultra (51.0 mol\%). Lecitase Ultra was immobilized on Duolite A658 via anion exchange and used in the hydrolysis or ethanolysis of phosphatidylcholine [182]. The study included several lipases, but the immobilized Lecitase Ultra offered the best results in ethanol. This biocatalyst was also used in the production of structured phosphatidylcholine via acidolysis of phosphatidylcholine with conjugated linoleic acid [183]. The incorporation of CLA reached $90 \%$, but this accounted for the product, as most of the substrate was hydrolyzed [183]. Later, this process was optimized by response surface methodology [184]. Other immobilization strategies were also assayed with Lecitase Ultra. When the enzyme was encapsulated in AOT/isooctane reverse micelles; the enzyme was located close to the interface [185]. Activity in esterification reactions increased after enzyme trapping. 
Lecitase Ultra was also trapped on Amberlites XAD2 (hydrophobic polymer) and XAD4 (no ionic polymer) using standard stirring or ultrasound irradiation [186]. The biocatalysts were used in production of monoglycerides from acidic residue from a palm oil refining using isopropylidene glycerol as second substrate. Yields of over 50\% were obtained under continuous flow conditions [186].

$$
\text { Lecitase Ultra was immobilized in a gelatin matrix, and this permitted a very }
$$
significant increase in the enantiospecificity of the enzyme versus ethyl 2-hydroxy-4-oxo-4phenylbutyrate (E value increases from 4.5 to 19.5 with S-enantiospecificity) [187]. The biocatalyst was also employed in the resolution of ethyl trans-( \pm )-3-phenyl glycidate and methyl trans-( \pm )-3-(4-methoxyphenyl) glycidate, yielding unreacted $(2 \mathrm{R}, 3 \mathrm{~S})$-glycidate esters with enantiomeric excess higher than $99 \%$ at conversion of $52-55 \%$. Later, the same group immobilized Lecitase Ultra on a macroporous gelatin organo-gel, achieving a yield of $47 \%$ yield [188]. This biocatalyst was employed to produce trans-(2R,3S) methyl (4methoxyphenyl)glycidate by enantiospecific hydrolysis of racemic glycidate ester The immobilized enzyme was reused several reaction batches maintaining the initial activity [188].

Another paper shows that Lecitase Ultra was immobilized in gelatin hydrogel and crosslinked with glutaraldehyde (activity recovery was more than 80\%) [189]. The immobilized biocatalyst presented a clear $\mathrm{pH}$-optimum of $\mathrm{pH} 7.5$, while the free enzyme has a broader $\mathrm{pH} /$ activity curve. Optimum temperature increased $13{ }^{\circ} \mathrm{C}$ after immobilization, and the stability increased greatly (maintained full activity under conditions where the free enzyme was fully inactivated). When used in a spinning basket bioreactor for the degumming of rice bran oil, it can be reused 6 times without significant changes in the activity (phosphorous reduction of 7-8 folds in each cycle). In another research, Lecitase Ultra 
was immobilized using calcium alginate (CA), calcium alginate-chitosan (CAC), and calcium alginate-gelatin $(\mathrm{CAG})$. After immobilization, the biocatalysts were treated with glutaraldehyde [190]. The best activity recovery was found using calcium alginate-gelatin. Thermal stability was increased after immobilization. The biocatalysts were used in degumming of soybean oil in a batch reactor, the reaction being slower using the immobilized enzyme preparations $(20 \%$ more time was required to reach the same results using calcium alginate-gelatin) [190].

Covalent immobilization has been also performed in many instances. Agarose containing vinylsulfone groups was used to immobilize Lecitase Ultra, with very disappointing results (the enzyme became inactivated after immobilization) [191].

\subsubsection{Immobilization of Lecitase Ultra on hydrophobic supports via interfacial activation}

A lipase immobilization method that has been used with many different lipases is the immobilization on hydrophobic supports via interfacial activation (Figure 1), that permits the one step immobilization, purification an stabilization of the enzyme [87]. The lipases immobilized this way have the open form stabilized versus the support surface [92]. This way, this is the immobilization protocol more utilized to immobilize lipases, and also Lecitase Ultra. Lecitase Ultra, as an interfacial enzyme, may be immobilized following this protocol. One of the most used supports to immobilize Lecitase Ultra is octyl-agarose beads, at least for academic purposes (although agarose may be applied at industrial level) [192].

The effect of the reaction medium composition on lipase stability has been found to be also very dependent on the exact immobilization preparation. For example, phosphate 
457

458

459

460

461

462

463

464

465

466

467 ions seem to have a very negative effect on lipase stability, and this is more significant when the enzyme is immobilized via interfacial activation [177]. The same case may be found using Lecitase Ultra, enzyme stability is greatly reduced in the presence of phosphate salts, although to a lower extent when compared to other immobilized enzymes [193]. On the other hand, some cations (e.g., $\mathrm{Ca}^{2+}$ ) seem to stabilize some lipases immobilized on hydrophobic supports via interfacial activation [194], although this effect depends on the exact immobilization support [195] and inactivation conditions [196]. However, this effect was not found using Lecitase Ultra [194]. Furthermore, enzyme stability did not significantly depend on Lecitase Ultra loading [197], although the effect of immobilization rate has not been properly evaluated using this enzyme [198], this result suggested that enzyme immobilization rate on octyl agarose was not as high as using some lipase.

Other hydrophobic supports have been used to immobilize Lecitase Ultra. Cellulose triacetate was used to immobilize Lecitase Ultra (yield near 100\%), taking advantage of the higher hydrophobicity if this product is compared to cellulose [199]. That way, the enzyme was immobilized via interfacial activation and the immobilized enzyme has higher thermostability than the free enzyme. Lecitase Ultra was also immobilized on Sepabeads C18 via interfacial activation and on Duolite via anion-exchange [200]. The biocatalysts were used in the catalysis of the ethanolysis of sardine oil in solvent-free medium. The enzyme immobilized via interfacial activation was 43 times more rapid in production of eicosapentaenoic ethyl esters than in the synthesis of docosahexaenoic ethyl ester. In another research, Lecitase Ultra was immobilized via interfacial activation on different core-shell supports, becoming the enzyme properties very dependent on the immobilization support [201]. Other example of the Lecitase Ultra immobilization via interfacial activation on some 
480 hydrophobic supports utilized some supports from Purolite company, like Lifetech ${ }^{\mathrm{TM}}$ 481 ECR1030M (DVB/methacrylic polymer), Lifetech ${ }^{\mathrm{TM}}$ ECR8804M (octadecyl methacrylate), 482 Lifetech ${ }^{\mathrm{TM}}$ ECR1061M (styrene/methacrylic polymer), Lifetech ${ }^{\mathrm{TM}}$ ECR8806M (octadecyl 483 methacylate) and Lifetech ${ }^{\mathrm{TM}}$ ECR1090M (styrene)) [202]. Results again show that enzyme 484 performance (activity, stability, specificity) strongly depends on the used support. These 485 biocatalyst were assayed in the production of biodiesel employing used cooking oil; results 486 were much worse than those obtained using the lipases from T. lanuginosus [203]. However, 487 it should be considered that this immobilized T. lanuginosus lipase biocatalyst gave values 488 near the alkaline catalysts [204]. Later on, the combination of Lecitase Ultra immobilized on 489 octadecyl methacylate and a proper phosphatidylcholine drying protocol improved the 490 previously described low conversion yields of phosphatidylcholine using Lecitase Ultra 491 immobilized on Duolite A658 [184], giving conversion yields over 95\% (by preventing the 492 hydrolysis) and reducing the reaction time from $24 \mathrm{~h}$ to $2 \mathrm{~h}$ (submitted manuscript).

494 in the esterification with different alcohols and acids under ultrasound conditions [205]. 495 Ultrasounds permitted to increase the enzyme activity by a factor over 2 . The best results 496 were obtained using of caprylic and myristic acids and ethanol. Another useful support to immobilize lipases is hydrophobic styrene498 divinylbenzene matrix. It has been used to immobilize Lecitase Ultra, and permits higher 499 loadings and immobilization rate than octyl-agarose [206].

500 Lecitase Ultra was also immobilized on hydrophobic polystyrene supports via 501 interfacial activation, improving the results achieved using other supports [207]. This 502 biocatalyst was later used in the glycerolysis of soybean oil ion solvent free system or using 
503 organic solvents as solvent [208]. Higher yields were obtained using solvent-free systems

504 (53.7 wt.\% if diglycerides in the lipid phase could be found).

505 Even though this strategy is very advantageous, it has a problem: the enzyme may

506 be released from the supports when using high temperature, organic solvents [209], or 507 detergent-like substrates/products [210]. Thus, some effort has been performed to overcome 508 this problem.

\subsubsection{Use of heterofunctional acyl supports to prevent enzyme release.}

One possibility is to modify the support, in a way that the first immobilization cause

512 remains the interfacial activation of the lipase on the hydrophobic support surface, but where

513 it is later possible to establish other enzyme-support interactions that prevent enzyme release.

514 Thus, Lecitase Ultra has been immobilized on glyoxyl-octyl agarose beads. This support 515 permits a first immobilization via interfacial activation (at neutral $\mathrm{pH}$ value) followed by 516 some covalent bond that prevents enzyme release (after incubation at alkaline $\mathrm{pH}$ value) 517 [209]. This improved the enzyme stability in thermal and organic solvent inactivation.

518 Lecitase Ultra immobilized on octyl and octyl-glyoxyl agarose beads were used in the 519 alcoholysis of tributirin with methanol, ethanol or isopropanol [211]. The phospholipase was 520 unable to produce isopropyl butyrate, while it could produce the other esters. However, the 521 paper shows how the combined use of high concentrations of alcohol and dibutyrin produced 522 the release of the enzyme from the octyl support, making the use of the covalent preparation 523 necessary [211]. 
Thus, this immobilization strategy solved the problem of undesired enzyme release.

525 However, it turns immobilization into an irreversible process. Thus, the support cannot be 526 reused after enzyme inactivation.

527 To solve this problem, ionic-acyl supports were designed. Octyl-glutamic [212], 528 and amino-octyl [213] heterofunctional agarose beads were used to reinforce the 529 immobilization of Lecitase Ultra and prevent enzyme desorption, while maintaining the 530 reversibility if the enzyme immobilization. The immobilization on these supports reduces 531 enzyme leakage and greatly alters the enzyme performance (stability, activity, specificity, 532 etc).

\subsubsection{Modulation of Lecitase Ultra properties via immobilization on different supports}

It has been reported that lipase catalytic properties may be dramatically modulated via immobilization on different supports or using different immobilization protocols [35].

537 Lecitase Ultra has been submitted to these strategies, where the researchers do not pay too 538 much attention to the immobilization process but on how the immobilization may affect the 539 enzyme properties.

Thus, Lecitase Ultra was immobilized in diverse supports following very different 541 immobilization mechanisms (octyl-agarose beads, cyanogen bromide agarose beads, 542 polyethylenimine coated agarose beads and glyoxyl agarose beads) and assayed in the 543 hydrolysis of ( \pm )-2-O-butanoyl-2-phenylacetic acid and ( \pm )-methyl mandelate, showing a 544 high alteration on the enzyme properties [214]. For example, the covalent preparation yielded 545 an $\mathrm{E}$ value of 26 , (the $\mathrm{S}$ isomer) while the enzyme immobilized on octyl agarose produced 546 mainly the R-mandelic acid (E value higher than 100). Similar biocatalysts were employed 
547 in the enantioselective hydrolysis of the prochiral dimethyl 3-phenylglutarate [215]. Again,

548 activity and accumulation of monoester were greatly depended on the immobilization

549 protocol. The enzyme covalently immobilized on cyanogen bromide agarose beads was the

550 most active and enantioselective biocatalyst, producing the (S)-methyl-3-phenylglutarate

551 with a yield of $80 \%$ and an ee exceeding $99 \%$ [215]. The same immobilized Lecitase Ultra

552 biocatalysts were used in the regioselective deprotection of 1,2,3,4,6-penta-O-acetyl- $\beta$-d-

553 galactopyranose, 2 -acetamido-2-deoxy-1,3,4,6-tetra-O-acetyl- $\beta$-d-glucopyranose , 1,2,3,4,6-

554 penta-O-acetyl- $\alpha$-d-mannopyranose and 2,3,4,6-tetra-O-acetyl- $\beta$-d-galacto pyranosyl-( $1 \rightarrow$

555 4)-1,2,3,6-tetra-O-acetyl- $\beta$-d-glucopyranoside [216]. Enzyme specificity and regio-

556 selectivity were tuned by the immobilization protocol. Different hydrophobic supports

557 (butyl- and octyl-agarose and hexyl- and butyl-Ttoyopearl) were used in Lecitase Ultra 558 immobilization [86]. Although the immobilization mechanism was the same (interfacial 559 activation), the different morphology, hydrophobicity, etc.

560 These results indicate that Lecitase Ultra properties can be modulated as deeply as 561 that of any other lipase using different immobilization protocols.

562

563 3.2. Physical or chemical modification of immobilized Lecitase Ultra to modulate 564 enzyme properties

565 Chemical and physical modification of immobilized enzymes may also be a tool to 566 tune enzyme properties, like activity, specificity or stability [29,30,217]. There are some 567 examples of immobilized Lecitase Ultra modification that promote very relevant alteration 568 on its performance as catalyst. 
570 beads and interfacially activated versus octyl-agarose beads were submitted to diverse

571 modifications (with 2,4,6-trinitrobenzensulfonic acid, glutaraldehyde or amination) [218].

572 Results showed than the effects of the chemical modifications on the enzyme features

573 significantly depended on the immobilization strategy used, in some instances the activity

574 increased while in others it decreased. Glutaraldehyde modification or amination

575 modification of immobilized Lecitase Ultra increased the enzyme stability of both

576 biocatalysts at pH 7 and 9 (around a 10-fold), while only the aminated biocatalyst increased

577 the enzyme stability at pH 5 by glutaraldehyde treatment.

578 In another research, the same biocatalysts (Lecitase Ultra covalently immobilized

579 on cyanogen bromide agarose and on octyl agarose biocatalysts) were coated with 580 polyethylenimine or dextran sulfate via ion exchange [219]. The cationic polymer increased

581 enzyme activity (e.g., by 30 folds using methyl phenyl acetate as substrate), while the anionic

582 polymer usually reduced enzyme activity. Both polymers permitted to increase the enzyme

583 stability in some conditions, mainly in organic solvents [219]. Later, the covalently

584 immobilized enzyme was incubated in some detergents that permitted to increase the enzyme

585 activity by inducing the Lecitase Ultra open form, and in that moment were incubated with

586 polyethylenimine, trying to freeze the open form of the Lecitase Ultra induced by the 587 detergents [220] (Figure 3). After detergent elimination, a significantly enhanced activity

588 (even by 50 times) was observed. The increase in the irreversible inhibition rate of the 589 enzyme by irreversible inhibitors suggested that the open form of the enzyme had been 590 stabilized.

\section{3.3. Coimmobilization of Lecitase and other enzymes}


594 gives some advantages in cascade reactions by eliminating the lag time required when using 595 independently immobilized enzymes. In some instances, this may become critical, affecting 596 not only the reaction rate but the final products yields (e.g., when the intermediate product is 597 unstable). However, together with other points, coimmobilization generates two significant 598 problems. The first one is that one enzyme is inactivated; the other enzymes must be also 599 discarded, even if they remain fully active. The second one is the necessity of using the same 600 support to immobilize all enzymes. The support that offers the best improvement of the 601 properties of one enzyme may not be the same that offers the best performance for the other 602 ones [36]. Recently, a strategy that may permit to avoid some of these problems has been 603 proposed, and Lecitase Ultra was involved as one of the utilized enzymes.

The strategy is to coimmobilize lipases and other enzymes (with lower stability and 605 hard to stabilize via immobilization), enabling the reuse of the immobilized lipase after the 606 inactivation of the other enzyme. This was initially described using a galactosidase and the 607 lipase B from Candida Antarctica [224]. The lipase was immobilized via interfacial 608 activation on octyl agarose, coated with polyethylenimine and then the galactosidase was 609 immobilized on the lipase-polyethylenimine molecule [224]. This permitted to reuse the 610 immobilized lipase after incubation of the immobilized co-biocatalyst at high ionic strength 611 and desorption of the inactivated galactosidase [225], that was much less stable than the 612 lipase, for several cycles. However, this has a problem: the PEI was desorbed along the 613 galactosidase, making it necessary to re-coat the enzyme with the polymer [224]. To solve 614 this problem, a more sophisticated protocol was proposed, using Lecitase Ultra as one of the 615 model enzymes. The idea was to obtain lipase-polyethylenimine composite resistant at high 
ion strength. To do this, the lipase-polymer bonds need to be covalent, using glutaraldehyde and glyoxyl-octyl agarose beads [226]. As a first study, the effect of the modification on immobilized Lecitase Ultra was investigated. Thus, Lecitase Ultra immobilized on octyl agarose was modified with PEI, then with glutaraldehyde, and their properties were analyzed, finding a small effect on enzyme activity but a clear stabilization [227] (Figure 4). The stabilization was more significant when modifying highly loaded preparations and using polyethylenimine. This paper shows by SDS-PAGE the promotion of multiple intermolecular polyethylenimine enzyme molecules cross-linking, confirming the hypothesis used to explain the stabilization of lipase preparations adsorbed on hydrophobic supports after modification with polyethylenimine. Now, the galactosidase can be immobilized via ion exchange on the PEI layer and may be desorbed without losing polyethylenimine from the biocatalyst and immobilized Lecitase Ultra may be re-used by several cycles without necessity of any additional modification [226].

\section{Conclusions}

Although Lecitase Ultra was initially designed for oil degumming and this has been among the main applications, the good properties of the enzyme (activity, specificity, stability) have greatly opened the range of likely applications. Lecitase Ultra may be handled as a standard lipase, and like them, can recognize a great diversity of substrates, very far from phospholipids. Thus, it should be considered in any screening of enzymes to catalyze the resolution of racemic esters, alcohols or carboxylic acids. One of the most promising applications is in the preparation of structured phospholipids, mainly in the preparation of different derivatives of lysophosphatidylcholine. Its immobilization on any hydrophobic support via interfacial activation makes it relatively simple to prepare home-made 
639 immobilized biocatalyst. This can avoid the lack of an immobilized Lecitase Ultra

640 immobilized preparation, very likely one of the main problems that is refraining the general

641 use of enzyme. It has also been showed how immobilization may greatly impact enzyme

642 activity, specificity or selectivity. Thus, it is expected that the applications of this enzyme,

643 both at academic and industrial scale, will continue the growth observed in the last years and

644 may become one of the most utilized enzymes.

645

646 Acknowledgments

647 We gratefully recognize the financial support from MINECO from Spanish Government 648 (project number CTQ2017-86170-R), Colciencias (Colombia, project number FP 44842649 076-2016), Generalitat Valenciana (PROMETEO/2018/076), FAPERGS (project number 650 17/2551-0000939-8), FUNCAP (project number BP3-0139-00005.01.00/18) and 651 CONACYT (Mexico, project number CB-2016-01, 286992). 
653

654

655

656

657

658

659

660

661

662

663

664

665

666

667

668

669

670

671

672

673

\section{References}

[1] N. Ran, L. Zhao, Z. Chen, J. Tao, Recent applications of biocatalysis in developing green chemistry for chemical synthesis at the industrial scale, Green Chem. 10 (2008) 361-372. doi:10.1039/b716045c.

[2] S. Sen, J.E. Puskas, Green polymer chemistry: Enzyme catalysis for polymer functionalization, Molecules. 20 (2015) 9358-9379.

doi:10.3390/molecules20059358.

[3] V.S. Ferreira-Leitão, M.C. Cammarota, E.C.G. Aguieiras, L.R.V. de Sá, R.

Fernandez-Lafuente, D.M.G. Freire, The protagonism of biocatalysis in green chemistry and its environmental benefits, Catalysts. 7 (2017) 9. doi:10.3390/catal7010009.

[4] R.A. Sheldon, Metrics of Green Chemistry and Sustainability: Past, Present, and Future, ACS Sustain. Chem. Eng. 6 (2018) 32-48.

doi:10.1021/acssuschemeng.7b03505.

[5] J. Li, J. Albrecht, A. Borovika, M.D. Eastgate, Evolving Green Chemistry Metrics into Predictive Tools for Decision Making and Benchmarking Analytics, ACS Sustain. Chem. Eng. 6 (2018) 1121-1132. doi:10.1021/acssuschemeng.7b03407.

[6] P. Anastas, N. Eghbali, Green Chemistry: Principles and Practice, Chem. Soc. Rev. 39 (2010) 301-312. doi:10.1039/B918763B.

[7] D.J.C. Constable, P.J. Dunn, J.D. Hayler, G.R. Humphrey, J.L. Leazer Jr., R.J. Linderman, K. Lorenz, J. Manley, B.A. Pearlman, A. Wells, A. Zaks, T.Y. Zhang, 
674

675

676

677

678

679

680

681

682

683

684

685

686

687

688

689

690

691

692

693

Key green chemistry research areas - A perspective from pharmaceutical manufacturers, Green Chem. 9 (2007) 411-420. doi:10.1039/b703488c.

[8] A. Schmid, J.S. Dordick, B. Hauer, A. Kiener, M. Wubbolts, B. Witholt, Industrial biocatalysis today and tomorrow, Nature. 409 (2001) 258-268.

[9] D.J. Pollard, J.M. Woodley, Biocatalysis for pharmaceutical intermediates: the future is now, Trends Biotechnol. 25 (2007) 66-73.

[10] M.T. Reetz, Biocatalysis in organic chemistry and biotechnology: Past, present, and future, J. Am. Chem. Soc. 135 (2013) 12480-12496. doi:10.1021/ja405051f.

[11] J.M. Woodley, New opportunities for biocatalysis: making pharmaceutical processes greener, Trends Biotechnol. 26 (2008) 321-327.

[12] A. Robles-Medina, P.A. González-Moreno, L. Esteban-Cerdán, E. Molina-Grima, Biocatalysis: Towards ever greener biodiesel production, Biotechnol. Adv. 27 (2009) 398-408. doi:10.1016/j.biotechadv.2008.10.008.

[13] R.N. Patel, Synthesis of chiral pharmaceutical intermediates by biocatalysis, Coord. Chem. Rev. 252 (2008) 659-701. doi:10.1016/j.ccr.2007.10.031.

[14] H.E. Schoemaker, Dispelling the Myths--Biocatalysis in Industrial Synthesis, Science. 299 (2003) 1694-1697. doi:10.1126/science.1079237.

[15] I.A. Castilla, D.F. Woods, F.J. Reen, F. O’Gara, Harnessing marine biocatalytic reservoirs for green chemistry applications through metagenomic technologies, Mar. Drugs. 16 (2018). doi:10.3390/md16070227. 
694

695

696

697

698

699

700

701

702

703

704

705

706

707

708

709

710

711

712

713

714
[16] C. Peña-García, M. Martínez-Martínez, D. Reyes-Duarte, M. Ferrer, High throughput screening of esterases, lipases and phospholipases in mutant and metagenomic libraries: A review, Comb. Chem. High Throughput Screen. 19 (2016) 605-615. doi:10.2174/1386207319666151110123927.

[17] D.A. Cowan, J.-B. Ramond, T.P. Makhalanyane, P. De Maayer, Metagenomics of extreme environments, Curr. Opin. Microbiol. 25 (2015) 97-102. doi:10.1016/j.mib.2015.05.005.

[18] L. Fernández-Arrojo, M.-E.E. Guazzaroni, N. López-Cortés, A. Beloqui, M. Ferrer, Metagenomic era for biocatalyst identification, Curr. Opin. Biotechnol. 21 (2010) 725-733. doi:10.1016/j.copbio.2010.09.006.

[19] M. Tuffin, D. Anderson, C. Heath, D.A. Cowan, Metagenomic gene discovery: How far have we moved into novel sequence space?, Biotechnol. J. 4 (2009) 1671-1683. doi:10.1002/biot.200900235.

[20] M. Ferrer, A. Beloqui, K.N. Timmis, P.N. Golyshin, Metagenomics for mining new genetic resources of microbial communities, J. Mol. Microbiol. Biotechnol. 16 (2008) 109-123. doi:10.1159/000142898.

[21] N.J. Turner, Directed evolution drives the next generation of biocatalysts, Nat. Chem. Biol. 5 (2009) 567-573.

[22] J.R. Cherry, A.L. Fidantsef, Directed evolution of industrial enzymes: An update, Curr. Opin. Biotechnol. 14 (2003) 438-443. doi:10.1016/S0958-1669(03)00099-5.

[23] P.A. Romero, F.H. Arnold, Exploring protein fitness landscapes by directed 
evolution, Nat. Rev. Mol. Cell Biol. 10 (2009) 866-876. doi:10.1038/nrm2805.

716

717

718

719

720

721

722

723

724

725

726

727

728

729

730

731

732

733

734

735

[24] V.G.H. Eijsink, S. Gåseidnes, T. V. Borchert, B. van den Burg, Directed evolution of enzyme stability, Biomol. Eng. 22 (2005) 21-30. doi:10.1016/j.bioeng.2004.12.003.

[25] F.H. Arnold, A.A. Volkov, Directed evolution of biocatalysts, Curr. Opin. Chem. Biol. 3 (1999) 54-59. doi:10.1016/S1367-5931(99)80010-6.

[26] C. Vieille, G.J. Zeikus, Hyperthermophilic enzymes: Sources, uses, and molecular mechanisms for thermostability, Microbiol. Mol. Biol. Rev. 65 (2001) 1-43. doi:10.1128/MMBR.65.1.1-43.2001.

[27] U.T. Bornscheuer, M. Pohl, Improved biocatalysts by directed evolution and rational protein design, Curr. Opin. Chem. Biol. 5 (2001) 137-143. doi:10.1016/S13675931(00)00182-4.

[28] K.L. Morley, R.J. Kazlauskas, Improving enzyme properties: When are closer mutations better?, Trends Biotechnol. 23 (2005) 231-237. doi:10.1016/j.tibtech.2005.03.005.

[29] R.C. Rodrigues, Á. Berenguer-Murcia, R. Fernandez-Lafuente, Coupling Chemical Modification and Immobilization to Improve the Catalytic Performance of Enzymes, Adv. Synth. Catal. 353 (2011) 2216-2238. doi:10.1002/adsc.201100163.

[30] N. Rueda, J.C.S. dos Santos, C. Ortiz, R. Torres, O. Barbosa, R.C. Rodrigues, Á. Berenguer-Murcia, R. Fernandez-Lafuente, Chemical Modification in the Design of Immobilized Enzyme Biocatalysts: Drawbacks and Opportunities, Chem. Rec. 16 (2016) 1436-1455. doi:10.1002/tcr.201600007. 
[31] C. Mateo, J.M. Palomo, G. Fernandez-Lorente, J.M. Guisan, R. Fernandez-Lafuente, Improvement of enzyme activity, stability and selectivity via immobilization techniques, Enzyme Microb. Technol. 40 (2007) 1451-1463.

[32] R.A. Sheldon, Enzyme immobilization: The quest for optimum performance, Adv. Synth. Catal. 349 (2007) 1289-1307. doi:10.1002/adsc.200700082.

[33] R.K. Singh, M.K. Tiwari, R. Singh, J.-K. Lee, From protein engineering to immobilization: Promising strategies for the upgrade of industrial enzymes, Int. J. Mol. Sci. 14 (2013) 1232-1277. doi:10.3390/ijms14011232.

[34] O. Barbosa, C. Ortiz, Á. Berenguer-Murcia, R. Torres, R.C. Rodrigues, R. Fernandez-Lafuente, Strategies for the one-step immobilization-purification of enzymes as industrial biocatalysts, Biotechnol. Adv. 33 (2015) 435-456. doi:10.1016/j.biotechadv.2015.03.006.

[35] R.C. Rodrigues, C. Ortiz, Á. Berenguer-Murcia, R. Torres, R. Fernández-Lafuente, Modifying enzyme activity and selectivity by immobilization, Chem. Soc. Rev. 42 (2013) 6290-6307. doi:10.1039/C2CS35231A.

[36] C. Garcia-Galan, Á. Berenguer-Murcia, R. Fernandez-Lafuente, R.C. Rodrigues, Potential of Different Enzyme Immobilization Strategies to Improve Enzyme Performance, Adv. Synth. Catal. 353 (2011) 2885-2904. doi:10.1002/adsc.201100534.

[37] D. Brady, J. Jordaan, Advances in enzyme immobilisation, Biotechnol. Lett. 31 (2009) 1639-1650. doi:10.1007/s10529-009-0076-4. 
757

758

759

760

761

762

763

764

765

766

767

768

769

770

771

772

773

774

775

776

777
[38] D.N. Tran, K.J. Balkus, Perspective of recent progress in immobilization of enzymes, ACS Catal. 1 (2011) 956-968.

[39] N.R. Mohamad, N.H.C. Marzuki, N.A. Buang, F. Huyop, R.A. Wahab, An overview of technologies for immobilization of enzymes and surface analysis techniques for immobilized enzymes, Biotechnol. Biotechnol. Equip. 29 (2015) 205-220. doi:10.1080/13102818.2015.1008192.

[40] U. Guzik, K. Hupert-Kocurek, D. Wojcieszynska, Immobilization as a strategy for improving enzyme properties- Application to oxidoreductases, Molecules. 19 (2014) 8995-9018.

[41] A.A. Homaei, R. Sariri, F. Vianello, R. Stevanato, Enzyme immobilization: An update, J. Chem. Biol. 6 (2013) 185-205. doi:10.1007/s12154-013-0102-9.

[42] M.T. Reetz, Lipases as practical biocatalysts, Curr. Opin. Chem. Biol. 6 (2002) 145150. doi:10.1016/S1367-5931(02)00297-1.

[43] P. Villeneuve, J.M. Muderhwa, J. Graille, M.J. Haas, Customizing lipases for biocatalysis: A survey of chemical, physical and molecular biological approaches, J. Mol. Catal. B Enzym. 9 (2000) 113-148. doi:10.1016/s1381-1177(99)00107-1.

[44] R. Zechner, R. Zimmermann, T.O. Eichmann, S.D. Kohlwein, G. Haemmerle, A. Lass, F. Madeo, FAT SIGNALS - Lipases and Lipolysis in Lipid Metabolism and Signaling, Cell Metab. 15 (2012) 279-291. doi:10.1016/j.cmet.2011.12.018.

[45] E.C.G. Aguieiras, D.S.N. de Barros, R. Fernandez-Lafuente, D.M.G. Freire, Production of lipases in cottonseed meal and application of the fermented solid as 
biocatalyst in esterification and transesterification reactions, Renew. Energy. 130 (2019) 574-581. doi:10.1016/j.renene.2018.06.095.

[46] H. Kim, N. Choi, Y. Kim, H.-R. Kim, J. Lee, I.-H. Kim, Immobilized lipasecatalyzed esterification for synthesis of trimethylolpropane triester as a biolubricant, Renew. Energy. 130 (2019) 489-494. doi:10.1016/j.renene.2018.06.092.

[47] M. Hümmer, S. Kara, A. Liese, I. Huth, J. Schrader, D. Holtmann, Synthesis of (-)menthol fatty acid esters in and from (-)-menthol and fatty acids - novel concept for lipase catalyzed esterification based on eutectic solvents, Mol. Catal. 458 (2018) $67-$ 72. doi:10.1016/j.mcat.2018.08.003.

[48] S. Cebrián-García, A.M. Balu, A. García, R. Luque, Sol-gel immobilisation of lipases: Towards active and stable biocatalysts for the esterification of valeric acid, Molecules. 23 (2018). doi:10.3390/molecules23092283.

[49] A. Foukis, O.A. Gkini, P.-Y. Stergiou, E.M. Papamichael, New insights and tools for the elucidation of lipase catalyzed esterification reaction mechanism in n-hexane: The synthesis of ethyl butyrate, Mol. Catal. 455 (2018) 159-163. doi:10.1016/j.mcat.2018.06.004.

[50] P.Y. Stergiou, A. Foukis, M. Filippou, M. Koukouritaki, M. Parapouli, L.G. Theodorou, E. Hatziloukas, A. Afendra, A. Pandey, E.M. Papamichael, Advances in lipase-catalyzed esterification reactions, Biotechnol. Adv. 31 (2013) 1846-1859. doi:10.1016/j.biotechadv.2013.08.006.

[51] P. Pires-Cabral, M.M.R. da Fonseca, S. Ferreira-Dias, Esterification activity and 
operational stability of Candida rugosa lipase immobilized in polyurethane foams in the production of ethyl butyrate, Biochem. Eng. J. 48 (2010) 246-252. doi:10.1016/j.bej.2009.10.021.

[52] A. Bajaj, P. Lohan, P.N. Jha, R. Mehrotra, Biodiesel production through lipase catalyzed transesterification: An overview, J. Mol. Catal. B Enzym. 62 (2010) 9-14. doi:10.1016/j.molcatb.2009.09.018.

[53] L. Li, W. Du, D. Liu, L. Wang, Z. Li, Lipase-catalyzed transesterification of rapeseed oils for biodiesel production with a novel organic solvent as the reaction medium, J. Mol. Catal. B Enzym. 43 (2006) 58-62. doi:10.1016/j.molcatb.2006.06.012.

[54] S. Shah, S. Sharma, M.N. Gupta, Biodiesel preparation by lipase-catalyzed transesterification of Jatropha oil, Energy and Fuels. 18 (2004) 154-159. doi:10.1021/ef030075z.

[55] N. Choi, D.S. No, H. Kim, B.H. Kim, J. Kwak, J.-S. Lee, I.-H. Kim, In situ lipasecatalyzed transesterification in rice bran for synthesis of fatty acid methyl ester, Ind. Crops Prod. 120 (2018) 140-146. doi:10.1016/j.indcrop.2018.04.049.

[56] I.A. Modenez, D.E. Sastre, F.C. Moares, C.G.C. Marques Netto, Influence of dlutaraldehyde cross-linking modes on the recyclability of immobilized lipase b from candida antarctica for transesterification of soy bean oil, Molecules. 23 (2018). doi:10.3390/molecules23092230.

[57] C.A. Palla, M.E. Carrín, Kinetics modeling of the acidolysis with immobilized 
Rhizomucor miehei lipases for production of structured lipids from sunflower oil, Biochem. Eng. J. 90 (2014) 184-194. doi:10.1016/j.bej.2014.06.006.

[58] S.M. Abed, X. Zou, A.H. Ali, Q. Jin, X. Wang, Synthesis of 1,3-dioleoyl-2arachidonoylglycerol-rich structured lipids by lipase-catalyzed acidolysis of microbial oil from Mortierella alpina, Bioresour. Technol. 243 (2017) 448-456. doi:10.1016/j.biortech.2017.06.090.

[59] S.M. Abed, W. Wei, A.H. Ali, S.A. Korma, A.H. Mousa, H.M. Hassan, Q. Jin, X. Wang, Synthesis of structured lipids enriched with medium-chain fatty acids via solvent-free acidolysis of microbial oil catalyzed by Rhizomucor miehei lipase, LWT - Food Sci. Technol. 93 (2018) 306-315. doi:10.1016/j.lwt.2018.03.057.

[60] A. Chojnacka, W. Gładkowski, Production of structured phosphatidylcholine with high content of myristic acid by lipase-catalyzed acidolysis and interesterification, Catalysts. 8 (2018). doi:10.3390/catal8070281.

[61] R. Sneha, T. Jeyarani, Lipase-catalysed acidolysis of mango kernel fat with capric acid to obtain medium- and long-chain triacylglycerols, Int. J. Food Sci. Technol. 53 (2018) 1527-1534. doi:10.1111/ijfs.13734.

[62] M. Rychlicka, N. Niezgoda, A. Gliszczyńska, Lipase-catalyzed acidolysis of eggyolk phosphatidylcholine with citronellic acid. New insight into synthesis of isoprenoid-phospholipids, Molecules. 23 (2018). doi:10.3390/molecules23020314.

[63] W. Xie, X. Zang, Immobilized lipase on core-shell structured Fe3O4-MCM-41 nanocomposites as a magnetically recyclable biocatalyst for interesterification of 
soybean oil and lard, Food Chem. 194 (2016) 1283-1292.

doi:10.1016/j.foodchem.2015.09.009.

[64] M.M. Soumanou, M. Pérignon, P. Villeneuve, Lipase-catalyzed interesterification reactions for human milk fat substitutes production: A review, Eur. J. Lipid Sci. Technol. 115 (2013) 270-285. doi:10.1002/ejlt.201200084.

[65] J.H. Lee, J.M. Son, C.C. Akoh, M.R. Kim, K.-T. Lee, Optimized synthesis of 1,3dioleoyl-2-palmitoylglycerol-rich triacylglycerol via interesterification catalyzed by a lipase from Thermomyces lanuginosus, N. Biotechnol. 27 (2010) 38-45. doi:10.1016/j.nbt.2009.10.006.

[66] W. Xie, X. Zang, Covalent immobilization of lipase onto aminopropylfunctionalized hydroxyapatite-encapsulated- $\gamma$-Fe2O3 nanoparticles: A magnetic biocatalyst for interesterification of soybean oil, Food Chem. 227 (2017) 397-403. doi:10.1016/j.foodchem.2017.01.082.

[67] B.P. Dwivedee, S. Soni, M. Sharma, J. Bhaumik, J.K. Laha, U.C. Banerjee, Promiscuity of Lipase-Catalyzed Reactions for Organic Synthesis: A Recent Update, ChemistrySelect. 3 (2018) 2441-2466. doi:10.1002/slct.201702954.

[68] S. Guezane-Lakoud, M. Toffano, L. Aribi-Zouioueche, Promiscuous lipase catalyzed a new $\mathrm{P}-\mathrm{C}$ bond formation: Green and efficient protocol for one-pot synthesis of $\alpha-$ aminophosphonates, Heteroat. Chem. 28 (2017). doi:10.1002/hc.21408.

[69] X. Hua, Y. Xing, X. Zhang, Enhanced Promiscuity of Lipase-Inorganic Nanocrystal Composites in the Epoxidation of Fatty Acids in Organic Media, ACS Appl. Mater. 
Interfaces. 8 (2016) 16257-16261. doi:10.1021/acsami.6b05061.

863

864

865

866

867

868

869

870

871

872

873

874

875

876

877

878

879

880

881

882

[70] D. González-Martínez, V. Gotor, V. Gotor-Fernández, Application of Deep Eutectic Solvents in Promiscuous Lipase-Catalysed Aldol Reactions, European J. Org. Chem. 2016 (2016) 1513-1519. doi:10.1002/ejoc.201501553.

[71] W. Li, R. Li, X. Yu, X. Xu, Z. Guo, T. Tan, S.N. Fedosov, Lipase-catalyzed Knoevenagel condensation in water-ethanol solvent system. Does the enzyme possess the substrate promiscuity?, Biochem. Eng. J. 101 (2015) 99-107. doi:10.1016/j.bej.2015.04.021.

[72] M. Kapoor, A.B. Majumder, M.N. Gupta, Promiscuous Lipase-Catalyzed C-C Bond Formation Reactions between 4 Nitrobenzaldehyde and 2-Cyclohexen-1-one in Biphasic Medium: Aldol and Morita-Baylis-Hillman Adduct Formations, Catal. Letters. 145 (2015) 527-532. doi:10.1007/s10562-014-1429-8.

[73] D.F. Izquierdo, O. Barbosa, M.I. Burguete, P. Lozano, S. V Luis, R. FernandezLafuente, E. Garcia-Verdugo, Tuning lipase B from Candida antarctica C-C bond promiscuous activity by immobilization on poly-styrene-divinylbenzene beads, RSC Adv. 4 (2014) 6219-6225. doi:10.1039/C3RA47069E.

[74] F. Yang, Z. Wang, H. Wang, H. Zhang, H. Yue, L. Wang, Enzyme catalytic promiscuity: Lipase catalyzed synthesis of substituted $2 \mathrm{H}$-chromenes by a threecomponent reaction, RSC Adv. 4 (2014) 25633-25636. doi:10.1039/c4ra03367a.

[75] M. Kapoor, M.N. Gupta, Lipase promiscuity and its biochemical applications, Process Biochem. 47 (2012) 555-569. doi:10.1016/j.procbio.2012.01.011. 
883

884

885

886

887

888

889

890

891

892

893

894

895

896

897

898

899

900

901

902

903

[76] R.D. Schmid, R. Verger, Lipases: Interfacial enzymes with attractive applications, Angew. Chemie, Int. Ed. 37 (1998) 1609-1633.

[77] A.M. Brzozowski, U. Derewenda, Z.S. Derewenda, G.G. Dodson, D.M. Lawson, J.P. Turkenburg, F. Bjorkling, B. Huge-Jensen, S.A. Patkar, L. Thim, A model for interfacial activation in lipases from the structure of a fungal lipase-inhibitor complex, Nature. 351 (1991) 491-494.

[78] H. Van Tilbeurgh, M.P. Egloff, C. Martinez, N. Rugani, R. Verger, C. Cambillau, Interfacial activation of the lipase-procolipase complex by mixed micelles revealed by X-ray crystallography, Nature. 362 (1993) 814-820.

[79] P. Grochulski, Y. Li, J.D. Schrag, F. Bouthillier, P. Smith, D. Harrison, B. Rubin, M. Cygler, Insights into interfacial activation from an open structure of Candida rugosa lipase, J. Biol. Chem. 268 (1993) 12843-12847.

[80] M. Martinelle, M. Holmquist, K. Hult, On the interfacial activation of Candida antarctica lipase A and B as compared with Humicola lanuginosa lipase, Biochim. Biophys. Acta - Lipids Lipid Metab. 1258 (1995) 272-276. doi:10.1016/00052760(95)00131-U.

[81] C. Chapus, M. Semeriva, C. Bovier-Lapierre, P. Desnuelle, Mechanism of pancreatic lipase action. 1. Interfacial activation of pancreatic lipase, Biochemistry. 15 (1976) 4980-4987. doi:10.1021/bi00668a006.

[82] M.L. Jennens, M.E. Lowe, A surface loop covering the active site of human pancreatic lipase influences interfacial activation and lipid binding, J. Biol. Chem. 
269 (1994) 25470-25474.

[83] N. Yaacob, N. Ahmad Kamarudin, A. Leow, A. Salleh, R. Raja Abd Rahman, M. Mohamad Ali, The Role of Solvent-Accessible Leu-208 of Cold-Active Pseudomonas fluorescens Strain AMS8 Lipase in Interfacial Activation, Substrate Accessibility and Low-Molecular Weight Esterification in the Presence of Toluene, Molecules. 22 (2017) 1312. doi:10.3390/molecules22081312.

[84] C. Cheng, T. Jiang, Y. Wu, L. Cui, S. Qin, B. He, Elucidation of lid open and orientation of lipase activated in interfacial activation by amphiphilic environment, Int. J. Biol. Macromol. 119 (2018) 1211-1217. doi:10.1016/j.ijbiomac.2018.07.158.

[85] J.M. Palomo, G. Muoz, G. Fernández-Lorente, C. Mateo, R. Fernández-Lafuente, J.M. Guisán, Interfacial adsorption of lipases on very hydrophobic support (octadecyl-Sepabeads): Immobilization, hyperactivation and stabilization of the open form of lipases, J. Mol. Catal. B Enzym. 19-20 (2002) 279-286. doi:10.1016/s13811177(02)00178-9.

[86] G. Fernandez-Lorente, Z. Cabrera, C. Godoy, R. Fernandez-Lafuente, J.M. Palomo, J.M. Guisan, Interfacially activated lipases against hydrophobic supports: Effect of the support nature on the biocatalytic properties, Process Biochem. 43 (2008) 10611067. doi:10.1016/j.procbio.2008.05.009.

[87] R. Fernandez-Lafuente, P. Armisén, P. Sabuquillo, G. Fernández-Lorente, J.M. Guisán, Immobilization of lipases by selective adsorption on hydrophobic supports, Chem. Phys. Lipids. 93 (1998) 185-197. doi:10.1016/s0009-3084(98)00042-5. 
[88] J.M. Palomo, M.M. Peñas, G. Fernández-Lorente, C. Mateo, A.G. Pisabarro, R. Fernández-Lafuente, L. Ramírez, J.M. Guisán, Solid-phase handling of hydrophobins: Immobilized hydrophobins as a new tool to study lipases, Biomacromolecules. 4 (2003) 204-210. doi:10.1021/bm0200711.

[89] J.M. Palomo, M. Fuentes, G. Fernández-Lorente, C. Mateo, J.M. Guisan, R. Fernández-Lafuente, General trend of lipase to self-assemble giving bimolecular aggregates greatly modifies the enzyme functionality, Biomacromolecules. 4 (2003) 1-6. doi:10.1021/bm025729+.

[90] G. Fernández-Lorente, J.M. Palomo, M. Fuentes, C. Mateo, J.M. Guisán, R. Fernández-Lafuente, Self-assembly of Pseudomonas fluorescens lipase into bimolecular aggregates dramatically affects functional properties, Biotechnol. Bioeng. 82 (2003) 232-237. doi:10.1002/bit.10560.

[91] J.M. Palomo, C. Ortiz, G. Fernández-Lorente, M. Fuentes, J.M. Guisán, R. Fernández-Lafuente, Lipase-lipase interactions as a new tool to immobilize and modulate the lipase properties, Enzyme Microb. Technol. 36 (2005) 447-454. doi:10.1016/j.enzmictec.2004.09.013.

[92] E.A. Manoel, J.C.S. dos Santos, D.M.G. Freire, N. Rueda, R. Fernandez-Lafuente, Immobilization of lipases on hydrophobic supports involves the open form of the enzyme, Enzyme Microb. Technol. 71 (2015) 53-57. doi:10.1016/j.enzmictec.2015.02.001.

[93] A. Kumar, K. Dhar, S.S. Kanwar, P.K. Arora, Lipase catalysis in organic solvents: Advantages and applications, Biol. Proced. Online. 18 (2016) 1-11. 
doi:10.1186/s12575-016-0033-2.

948

949

950

951

952

953

954

955

956

957

958

959

960

961

962

963

964

965

966

967
[94] T. Kobayashi, S. Adachi, Reaction equilibrium for lipase-catalyzed condensation in organic solvent systems, Biotechnol. Lett. 26 (2004) 1461-1468. doi:10.1023/B:BILE.0000044481.31933.5d.

[95] I. Juneidi, M. Hayyan, M.A. Hashim, Intensification of biotransformations using deep eutectic solvents: Overview and outlook, Process Biochem. 66 (2018) 33-60. doi:10.1016/j.procbio.2017.12.003.

[96] P. Xu, G.-W. Zheng, M.-H. Zong, N. Li, W.-Y. Lou, Recent progress on deep eutectic solvents in biocatalysis, Bioresour. Bioprocess. 4 (2017). doi:10.1186/s40643-017-0165-5.

[97] H. Taher, S. Al-Zuhair, The use of alternative solvents in enzymatic biodiesel production: a review, Biofuels, Bioprod. Biorefining. 11 (2017) 168-194. doi:10.1002/bbb.1727.

[98] E. Durand, J. Lecomte, P. Villeneuve, Deep eutectic solvents: Synthesis, application, and focus on lipase-catalyzed reactions, Eur. J. Lipid Sci. Technol. 115 (2013) 379385. doi:10.1002/ejlt.201200416.

[99] A. Ghanem, H.Y. Aboul-Enein, Lipase-mediated chiral resolution of racemates in organic solvents, Tetrahedron: Asymmetry. 15 (2004) 3331-3351. doi:10.1016/j.tetasy.2004.09.019.

[100] L.-E. Meyer, J. von Langermann, U. Kragl, Recent developments in biocatalysis in multiphasic ionic liquid reaction systems, Biophys. Rev. 10 (2018) 901-910. 
doi:10.1007/s12551-018-0423-6.

969

970

971

972

973

974

975

976

977

978

979

980

981

982

983

984

985

986

987

988
[101] A.A. Elgharbawy, F.A. Riyadi, M.Z. Alam, M. Moniruzzaman, Ionic liquids as a potential solvent for lipase-catalysed reactions: A review, J. Mol. Liq. 251 (2018) 150-166. doi:10.1016/j.molliq.2017.12.050.

[102] T. Itoh, Ionic liquids as tool to improve enzymatic organic synthesis, Chem. Rev. 117 (2017) 10567-10607. doi:10.1021/acs.chemrev.7b00158.

[103] R.A. Sheldon, Biocatalysis and Biomass Conversion in Alternative Reaction Media, Chem. - A Eur. J. 22 (2016) 12984-12999. doi:10.1002/chem.201601940.

[104] A.L.B. Dias, P. dos Santos, J. Martínez, Supercritical CO2 technology applied to the production of flavor ester compounds through lipase-catalyzed reaction: A review, J. CO2 Util. 23 (2018) 159-178. doi:10.1016/j.jcou.2017.11.011.

[105] R.E. Gumba, S. Saallah, M. Misson, C.M. Ongkudon, A. Anton, Green biodiesel production: A review on feedstock, catalyst, monolithic reactor, and supercritical fluid technology, Biofuel Res. J. 3 (2016) 431-447. doi:10.18331/BRJ2016.3.3.3.

[106] T. Matsuda, Recent progress in biocatalysis using supercritical carbon dioxide, J. Biosci. Bioeng. 115 (2013) 233-241. doi:10.1016/j.jbiosc.2012.10.002.

[107] A. Aloulou, Y. Ben Ali, S. Bezzine, Y. Gargouri, M.H. Gelb, Phospholipases: An Overview, in: G. Sandoval (Ed.), Lipases Phospholipases. Methods Mol. Biol. (Methods Protoc., v. 186, Humana Press, New York, NY, United States, 2012: pp. 63-85. doi:10.1007/978-1-61779-600-5_4.

[108] L. De Maria, J. Vind, K.M. Oxenbøll, A. Svendsen, S. Patkar, Phospholipases and 
their industrial applications, Appl. Microbiol. Biotechnol. 74 (2007) 290-300. doi:10.1007/s00253-006-0775-x.

[109] A. Bourtsala, D. Galanopoulou, Phospholipases, in: L. Melton, F. Shahidi, P. Varelis (Eds.), Encycl. Food Chem., Academic Press, 2019: pp. 277-286. doi:10.1016/B978-0-08-100596-5.21651-X.

[110] G. Borrelli, D. Trono, Recombinant Lipases and Phospholipases and Their Use as Biocatalysts for Industrial Applications, Int. J. Mol. Sci. 16 (2015) 20774-20840. doi:10.3390/ijms160920774.

[111] L.B. Silveira, D.P. Marchi-Salvador, N.A. Santos-Filho, F.P. Silva, S. Marcussi, A.L. Fuly, A. Nomizo, S.L. da Silva, R.G. Stábeli, E.C. Arantes, A.M. Soares, Isolation and expression of a hypotensive and anti-platelet acidic phospholipase A2 from Bothrops moojeni snake venom, J. Pharm. Biomed. Anal. 73 (2013) 35-43. doi:10.1016/j.jpba.2012.04.008.

[112] L. Su, D. Ji, X. Tao, L. Yu, J. Wu, Y. Xia, Recombinant expression, characterization, and application of a phospholipase B from Fusarium oxysporum, J. Biotechnol. 242 (2017) 92-100. doi:10.1016/j.jbiotec.2016.12.009.

[113] X. Fang, X. Wang, G. Li, J. Zeng, J. Li, J. Liu, SS-mPEG chemical modification of recombinant phospholipase $\mathrm{C}$ for enhanced thermal stability and catalytic efficiency, Int. J. Biol. Macromol. 111 (2018) 1032-1039. doi:10.1016/j.ijbiomac.2018.01.134.

[114] Y. Liu, L. Huang, Y. Fu, D. Zheng, J. Ma, Y. Li, Z. Xu, F. Lu, A novel process for phosphatidylserine production using a Pichia pastoris whole-cell biocatalyst with 
1010

1011

1012

1013

1014

1015

1016

1017

1018

1019

1020

1021

1022

1023

1024

1025

1026

1027

1028

1029

1030

overexpression of phospholipase D from Streptomyces halstedii in a purely aqueous system, Food Chem. 274 (2019) 535-542. doi:10.1016/j.foodchem.2018.08.105.

[115] F. Jiang, J. Wang, L. Ju, I. Kaleem, D. Dai, C. Li, Optimization of degumming process for soybean oil by phospholipase B, J. Chem. Technol. Biotechnol. 86 (2011) 1081-1087. doi:10.1002/jctb.2621.

[116] L.R. Gerits, B. Pareyt, K. Decamps, J.A. Delcour, Lipases and Their Functionality in the Production of Wheat-Based Food Systems, Compr. Rev. Food Sci. Food Saf. 13 (2014) 978-989. doi:10.1111/1541-4337.12085.

[117] H.M. Lilbæk, T.M. Fatum, R. Ipsen, N.K. Sørensen, Modification of Milk and Whey Surface Properties by Enzymatic Hydrolysis of Milk Phospholipids, J. Agric. Food Chem. 55 (2007) 2970-2978. doi:10.1021/jf062705b.

[118] V. Casado, D. Martín, C. Torres, G. Reglero, Phospholipases in Food Industry: A Review, in: G. Sandoval (Ed.), Lipases Phospholipases. Methods Mol. Biol. (Methods Protoc., v. 186, Humana Press, New York, NY, United States, 2012: pp. 495-523. doi:10.1007/978-1-61779-600-5_29.

[119] K. Clausen, C.C. Fuglsang, K. Borch, S.A. Patkar, Enzymatic oil degumming and lysolecithin preparation by novel microbial phospholipasese, in: 89th AOCS Annu. Meet. Expo, Chicago, 1998.

[120] K. Zhang, L. Zhang, X. Wang, L. Qu, Y. Liu, Amino acid sequence analysis and catalytic mechanism of Lecitase Ultra, J. Chinese Cereal. Oils Assoc. 31 (2016) 7074 and 80. 
1031

1032

1033

1034

1035

1036

1037

1038

1039

1040

1041

1042

1043

1044

1045

1046

1047

1048

1049

1050

1051
[121] A.J. Dijkstra, Enzymatic degumming, Eur. J. Lipid Sci. Technol. 112 (2010) 11781189. doi:10.1002/ejlt.201000320.

[122] A.J. Dijkstra, Degumming, refining, washing and drying fats and oils, in: T.H. Applewhite (Ed.), Proc. World Conf. Oilseed Technol. Util., The American Oil Chemists Society, Champaign, IL, 1993: pp. 138-151.

[123] Y. Xu, G. Wang, C. Li, D. Dai, Application of enzymatic degumming on vegetable oils refining, Nongye Gongcheng Xuebao/Transactions Chinese Soc. Agric. Eng. 31 (2015) 269-276. doi:10.11975/j.issn.1002-6819.2015.23.036.

[124] F. Wang, H. Zhang, Y. Liu, F.I. Khan, B. Yang, Y. Wang, Profiling substrate specificity of Lecitase Ultra to different kinds of phospholipids using monolayer technology, Eur. J. Lipid Sci. Technol. 119 (2017). doi:10.1002/ejlt.201600175.

[125] J.-G.G. Yang, Y.-H.H. Wang, B. Yang, G. Mainda, Y. Guo, Degumming of vegetable oil by a new microbial lipase, Food Technol. Biotechnol. 44 (2006) 101104.

[126] S. Manjula, A. Jose, S. Divakar, R. Subramanian, Degumming rice bran oil using phospholipase-A1, Eur. J. Lipid Sci. Technol. 113 (2011) 658-664. doi:10.1002/ejlt.201000376.

[127] D.L. Lamas, G.H. Crapiste, D.T. Constenla, Changes in quality and composition of sunflower oil during enzymatic degumming process, LWT - Food Sci. Technol. 58 (2014) 71-76. doi:10.1016/j.lwt.2014.02.024.

[128] K.A. Sampaio, N. Zyaykina, B. Wozniak, J. Tsukamoto, W. De Greyt, C. V. 
1052

1053

1054

1055

1056

1057

1058

1059

1060

1061

1062

1063

1064

1065

1066

1067

1068

1069

1070

1071

1072
Stevens, Enzymatic degumming: Degumming efficiency versus yield increase, Eur. J. Lipid Sci. Technol. 117 (2015) 81-86. doi:10.1002/ejlt.201400218.

[129] M.L. Goñi, C. Pacheco, D.T. Constenla, A.A. Carelli, Solvent-free enzymatic hydrolysis of non-polar lipids in crude sunflower lecithin using phospholipase A1 (Lecitase ${ }^{\circledR}$ Ultra), Biocatal. Biotransformation. 36 (2018) 341-351. doi:10.1080/10242422.2017.1376662.

[130] H.-J. Bang, I.-H. Kim, B.H. Kim, Phospholipase A1-catalyzed hydrolysis of soy phosphatidylcholine to prepare $1-\alpha$-glycerylphosphorylcholine in organic-aqueous media, Food Chem. 190 (2016) 201-206. doi:10.1016/j.foodchem.2015.05.093.

[131] K. Zhang, Y. Liu, X. Wang, Enzymatic preparation of L- $\alpha-$ glycerylphosphorylcholine in an aqueous medium, Eur. J. Lipid Sci. Technol. 114 (2012) 1254-1260. doi:10.1002/ejlt.201100219.

[132] K. Zhang, L. Zhang, X. Wang, Y. Liu, The hydrolysis of phosphatidylcholine by phospholipase A1 (Lecitase Ultra) through the kinetic and thermodynamic, J. Chinese Cereal. Oils Assoc. 31 (2016) 76-80.

[133] C.W. Lim, B.H. Kim, I.-H. Kim, M.-W. Lee, Modeling and optimization of phospholipase A1-catalyzed hydrolysis of phosphatidylcholine using response surface methodology for lysophosphatidylcholine production, Biotechnol. Prog. 31 (2015) 35-41. doi:10.1002/btpr.2009.

[134] G. Yang, R. Yang, Y. Bi, S. Sun, J. Chen, Preparation of the lysophosphatidylcholine by phospholipase A1-catalyzed ethanolysis of soybean 
phosphatidylcholine in hexane, J. Chinese Cereal. Oils Assoc. 31 (2016) 64-68.

1074

1075

1076

1077

1078

1079

1080

1081

1082

1083

1084

1085

1086

1087

1088

1089

1090

1091

1092

1093
[135] V.R. Murty, J. Bhat, P.K.A. Muniswaran, Hydrolysis of oils by using immobilized lipase enzyme: A review, Biotechnol. Bioprocess Eng. 7 (2002) 57-66.

[136] D. Goswami, J.K. Basu, S. De, Lipase applications in oil hydrolysis with a case study on castor oil: A review, Crit. Rev. Biotechnol. 33 (2013) 81-96.

[137] M. Mardani, J. Farmani, R.E. Kenari, Efficacy of some commercial lipases in hydrolysis of palm olein for the production of free fatty acids and diacylglycerol oil, J. Oil Palm Res. 27 (2015) 250-260.

[138] Y. Wang, M. Zhao, K. Song, L. Wang, X. Han, S. Tang, Y. Wang, Separation of diacylglycerols from enzymatically hydrolyzed soybean oil by molecular distillation, Sep. Purif. Technol. 75 (2010) 114-120. doi:10.1016/j.seppur.2010.08.012.

[139] Y. Wang, M. Zhao, K. Song, L. Wang, S. Tang, W.W. Riley, Partial hydrolysis of soybean oil by phospholipase A1 (Lecitase Ultra), Food Chem. 121 (2010) 10661072. doi:10.1016/j.foodchem.2010.01.051.

[140] Y. Wang, M. Zhao, S. Ou, K. Song, X. Han, Preparation of diacylglycerol-enriched palm olein by phospholipase A1-catalyzed partial hydrolysis, Eur. J. Lipid Sci. Technol. 111 (2009) 652-662. doi:10.1002/ejlt.200800294.

[141] Y. Wang, M. Zhao, S. Ou, K. Song, Partial hydrolysis of soybean oil by phospholipase A1 to produce diacylglycerol-enriched oil, J. Food Lipids. 16 (2009) 113-132. doi:10.1111/j.1745-4522.2009.01136.x.

[142] Y. Wang, M. Zhao, S. OU, L. Xie, S. Tang, Preparation of a diacylglycerol-enriched 
soybean oil by phosphalipase A1 catalyzed hydrolysis, J. Mol. Catal. B Enzym. 56 (2009) 165-172. doi:10.1016/j.molcatb.2008.07.008.

[143] Y. Wang, M. Zhao, S. Tang, K. Song, X. Han, S. Ou, Evaluation of the Oxidative Stability of Diacylglycerol-Enriched Soybean Oil and Palm Olein Under RancimatAccelerated Oxidation Conditions, J. Am. Oil Chem. Soc. 87 (2010) 483-491. doi:10.1007/s11746-009-1521-1.

[144] N. Liu, Y. Wang, Q. Zhao, M. Zhao, Production of palm oil-based diacylglycerol using Lecitase Ultra-catalyzed glycerolysis and molecular distillation, Food Sci. Biotechnol. 23 (2014) 365-371. doi:10.1007/s10068-014-0051-2.

[145] L. Wang, Y. Wang, C. Hu, Q. Cao, X. Yang, M. Zhao, Preparation of Diacylglycerol-Enriched Oil from Free Fatty Acids Using Lecitase Ultra-Catalyzed Esterification, J. Am. Oil Chem. Soc. 88 (2011) 1557-1565. doi:10.1007/s11746011-1821-0.

[146] N. Liu, Y. Wang, Q. Zhao, Q. Zhang, M. Zhao, Fast synthesis of 1,3-DAG by Lecitase ${ }^{\circledR}$ Ultra-catalyzed esterification in solvent-free system, Eur. J. Lipid Sci. Technol. 113 (2011) 973-979. doi:10.1002/ejlt.201000507.

[147] S. Melis, A. Pauly, J.A. Delcour, Impact of lipases with different substrate specificity in wheat flour separation on the properties of the resultant gluten, $\mathrm{J}$. Cereal Sci. 77 (2017) 291-296. doi:10.1016/j.jcs.2017.08.024.

[148] S. Melis, A. Pauly, L.R. Gerits, B. Pareyt, J.A. Delcour, Lipases as Processing Aids in the Separation of Wheat Flour into Gluten and Starch: Impact on the Lipid 
Population, Gluten Agglomeration, and Yield, J. Agric. Food Chem. 65 (2017) 1932-1940. doi:10.1021/acs.jafc.6b04955.

[149] L.R. Gerits, B. Pareyt, H.G. Masure, J.A. Delcour, A lipase based approach to understand the role of wheat endogenous lipids in bread crumb firmness evolution during storage, LWT - Food Sci. Technol. 64 (2015) 874-880. doi:10.1016/j.lwt.2015.06.055.

[150] L.R. Gerits, B. Pareyt, H.G. Masure, J.A. Delcour, Native and enzymatically modified wheat (Triticum aestivum L.) endogenous lipids in bread making: A focus on gas cell stabilization mechanisms, Food Chem. 172 (2015) 613-621. doi:10.1016/j.foodchem.2014.09.064.

[151] L.R. Gerits, B. Pareyt, J.A. Delcour, Wheat starch swelling, gelatinization and pasting: Effects of enzymatic modification of wheat endogenous lipids, LWT - Food Sci. Technol. 63 (2015) 361-366. doi:10.1016/j.lwt.2015.02.035.

[152] S. Al Sharqi, N.T. Dunford, C. Goad, Enzymatic Wheat Germ Oil Degumming, Trans. ASABE. 58 (2015) 1867-1872. doi:10.13031/trans.58.11032.

[153] L.R. Gerits, B. Pareyt, J.A. Delcour, A lipase based approach for studying the role of wheat lipids in bread making, Food Chem. 156 (2014) 190-196. doi:10.1016/j.foodchem.2014.01.107.

[154] T.M. Mata, F. Pinto, N. Caetano, A.A. Martins, Economic and environmental analysis of animal fats acidity reduction by enzymatic esterification, J. Clean. Prod. 184 (2018) 481-489. doi:10.1016/j.jclepro.2018.02.253. 
1136

1137

1138

1139

1140

1141

1142

1143

1144

1145

1146

1147

1148

1149

1150

1151

1152

1153

1154

1155

1156
[155] S. Granafei, I. Losito, F. Palmisano, T.R.I. Cataldi, Unambiguous regiochemical assignment of sulfoquinovosyl mono- and diacylglycerols in parsley and spinach leaves by liquid chromatography/electrospray ionization sequential mass spectrometry assisted by regioselective enzymatic hydrolysis, Rapid Commun. Mass Spectrom. 31 (2017) 1499-1509. doi:10.1002/rcm.7928.

[156] M. Vergara-Barberán, M.J. Lerma-García, J.M. Herrero-Martínez, E.F. SimóAlfonso, Efficient Extraction of Olive Pulp and Stone Proteins by using an EnzymeAssisted Method, J. Food Sci. 79 (2014) C1298-C1304. doi:10.1111/17503841.12499.

[157] S.S.S. Havn, R. Ipsen, P.M.M. Nielsen, H.M.M. Lilbæk, Improving the foaming properties and heat stability of whey protein concentrates by phospholipase treatment, Milchwissenschaft. 61 (2006) 188-191.

[158] A. Ghanem, Trends in lipase-catalyzed asymmetric access to enantiomerically pure/enriched compounds, Tetrahedron. 63 (2007) 1721-1754. doi:10.1016/j.tet.2006.09.110.

[159] A. Liljeblad, L.T. Kanerva, Biocatalysis as a profound tool in the preparation of highly enantiopure $\beta$-amino acids, Tetrahedron. 62 (2006) 5831-5854.

[160] S. Serra, C. Fuganti, E. Brenna, Biocatalytic preparation of natural flavours and fragrances, Trends Biotechnol. 23 (2005) 193-198. doi:10.1016/j.tibtech.2005.02.003.

[161] A.M. Gumel, M.S.M. Annuar, Thermomyces lanuginosus lipase-catalyzed synthesis 
of natural flavor esters in a continuous flow microreactor, 3 Biotech. 6 (2016) 24. doi:10.1007/s13205-015-0355-9.

[162] A. Ghanem, H.Y. Aboul-Enein, Application of lipases in kinetic resolution of racemates, Chirality. 17 (2005) 1-15. doi:10.1002/chir.20089.

[163] A. Leśniarek, A. Chojnacka, W. Gładkowski, Application of Lecitase $®$ UltraCatalyzed Hydrolysis to the Kinetic Resolution of (E)-4-phenylbut-3-en-2-yl Esters, Catalysts. 8 (2018) 423. doi:10.3390/catal8100423.

[164] I.K. Varma, A.-C. Albertsson, R. Rajkhowa, R.K. Srivastava, Enzyme catalyzed synthesis of polyesters, Prog. Polym. Sci. 30 (2005) 949-981. doi:10.1016/j.progpolymsci.2005.06.010.

[165] S. Kobayashi, Recent Developments in Lipase-Catalyzed Synthesis of Polyesters, Macromol. Rapid Commun. 30 (2009) 237-266. doi:10.1002/marc.200800690.

[166] A.M. Gumel, M.S.M. Annuar, Y. Chisti, Lipase catalyzed ultrasonic synthesis of poly-4-hydroxybutyrate-co-6-hydroxyhexanoate, Ultrason. Sonochem. 20 (2013) 937-947. doi:10.1016/j.ultsonch.2012.09.015.

[167] A.M. Gumel, M.S.M. Annuar, T. Heidelberg, Enzymatic synthesis of 6-O-glucosylpoly(3-hydroxyalkanoate) in organic solvents and their binary mixture, Int. J. Biol. Macromol. 55 (2013) 127-136. doi:10.1016/j.ijbiomac.2012.12.028.

[168] C. Chuensangjun, C. Pechyen, S. Sirisansaneeyakul, Degradation Behaviors of Different Blends of Polylactic Acid Buried in Soil, Energy Procedia. 34 (2013) 7382. doi:10.1016/j.egypro.2013.06.735. 
1178

1179

1180

1181

1182

1183

1184

1185

1186

1187

1188

1189

1190

1191

1192

1193

1194

1195

1196

1197

1198
[169] S. Hama, H. Noda, A. Kondo, How lipase technology contributes to evolution of biodiesel production using multiple feedstocks, Curr. Opin. Biotechnol. 50 (2018) 57-64. doi:10.1016/j.copbio.2017.11.001.

[170] E.C.G. Aguieiras, E.D. Cavalcanti-Oliveira, D.M.G. Freire, Current status and new developments of biodiesel production using fungal lipases, Fuel. 159 (2015) 52-67. doi:10.1016/j.fuel.2015.06.064.

[171] X. Zhao, F. Qi, C. Yuan, W. Du, D. Liu, Lipase-catalyzed process for biodiesel production: Enzyme immobilization, process simulation and optimization, Renew. Sustain. Energy Rev. 44 (2015) 182-197. doi:10.1016/j.rser.2014.12.021.

[172] R. Sankaran, P.L. Show, J.-S. Chang, Biodiesel production using immobilized lipase: feasibility and challenges, Biofuels, Bioprod. Biorefining. 10 (2016) 896916. doi:10.1002/bbb.1719.

[173] N. Kumar, A.S. Singh, S. Kumari, M.P. Reddy, Biotechnological approaches for the genetic improvement of Jatropha curcas L.: A biodiesel plant, Ind. Crops Prod. 76 (2015) 817-828. doi:10.1016/j.indcrop.2015.07.028.

[174] B.Y. Lim, R. Shamsudin, B.T.H.T. Baharudin, R. Yunus, A review of processing and machinery for Jatropha curcas L. fruits and seeds in biodiesel production: Harvesting, shelling, pretreatment and storage, Renew. Sustain. Energy Rev. 52 (2015) 991-1002. doi:10.1016/j.rser.2015.07.077.

[175] G. Gofferjé, J. Motulewicz, A. Stäbler, T. Herfellner, U. Schweiggert-Weisz, E. Flöter, Enzymatic Degumming of Crude Jatropha Oil: Evaluation of Impact Factors 
on the Removal of Phospholipids, J. Am. Oil Chem. Soc. 91 (2014) 2135-2141. doi:10.1007/s11746-014-2559-2.

[176] Y. Li, Y. Huang, W. Du, L. Dai, D. Liu, Combined phospholipase and lipase catalysis for biodiesel production from phospholipids-containing oil, Biotechnol. Bioprocess Eng. 20 (2015) 965-970. doi:10.1007/s12257-015-0250-6.

[177] S. Arana-Peña, Y. Lokha, R. Fernández-Lafuente, Immobilization of Eversa Lipase on Octyl Agarose Beads and Preliminary Characterization of Stability and Activity Features, Catalysts. 8 (2018) 511. doi:10.3390/catal8110511.

[178] R. Drozd, M. Szymańska, R. Rakoczy, A. Junka, P. Szymczyk, K. Fijałkowski, Functionalized Magnetic Bacterial Cellulose Beads as Carrier for Lecitase ${ }^{\circledR}$ Ultra Immobilization, Appl. Biochem. Biotechnol. 187 (2019) 176-193. doi:10.1007/s12010-018-2816-1.

[179] T. Kumaraguru, T. Harini, S. Basetty, Immobilization of Lecitase® ultra on recyclable polymer support: application in resolution of trans-methyl (4methoxyphenyl)glycidate in organic solvents, Tetrahedron: Asymmetry. 28 (2017) 1612-1617. doi:10.1016/j.tetasy.2017.10.006.

[180] J.C.J. Quilles, R.R. Brito, J.P. Borges, C.C. Aragon, G. Fernandez-Lorente, D.A. Bocchini-Martins, E. Gomes, R. da Silva, M. Boscolo, J.M. Guisan, Modulation of the activity and selectivity of the immobilized lipases by surfactants and solvents, Biochem. Eng. J. 93 (2015) 274-280. doi:10.1016/j.bej.2014.10.009. 
Lee, Emulsifying Properties of Lecithin Containing Different Fatty Acids Obtained by Immobilized Lecitase Ultra-Catalyzed Reaction, J. Am. Oil Chem. Soc. 91 (2014) 579-590. doi:10.1007/s11746-013-2396-8.

[182] R. Baeza-Jiménez, L.X. López-Martínez, C. Otero, I.-H. Kim, H.S. García, Enzymecatalysed hydrolysis of phosphatidylcholine for the production of lysophosphatidylcholine, J. Chem. Technol. Biotechnol. 88 (2013) 1859-1863. doi: $10.1002 /$ jctb.4040.

[183] R. Baeza-Jiménez, J. González-Rodríguez, I.-H. Kim, H.S. García, C. Otero, Use of immobilized phospholipase A1-catalyzed acidolysis for the production of structured phosphatidylcholine with an elevated conjugated linoleic acid content, Grasas y Aceites. 63 (2012) 44-52. doi:10.3989/gya.045211.

[184] R. Baeza-Jiménez, J.A. Noriega-Rodríguez, H.S. García, C. Otero, Structured phosphatidylcholine with elevated content of conjugated linoleic acid: Optimization by response surface methodology, Eur. J. Lipid Sci. Technol. 114 (2012) 1261-1267. doi:10.1002/ejlt.201200038.

[185] K.M. Gonçalves, I.I. Junior, V. Papadimitriou, M. Zoumpanioti, I.C.R. Leal, R.O.M.A. de Souza, Y. Cordeiro, A. Xenakis, Nanoencapsulated Lecitase Ultra and Thermomyces lanuginosus Lipase, a Comparative Structural Study, Langmuir. 32 (2016) 6746-6756. doi:10.1021/acs.langmuir.6b00826.

[186] K.M. Gonçalves, F.K. Sutili, I.I. Júnior, M.C. Flores, L. Soter De Mariz E Miranda, I.C.R. Leal, Y. Cordeiro, R. Luque, R.O.M.A. De Souza, A Comprehensive Study on the Activity and Deactivation of Immobilized Lecitase Ultra in Esterifications of 
Food Waste Streams to Monoacylglycerols, ChemSusChem. 6 (2013) 872-879. doi:10.1002/cssc.201300026.

[187] M.K. Mishra, T. Kumaraguru, G. Sheelu, N.W. Fadnavis, Lipase activity of Lecitase $\AA^{\text {Ultra: }}$ characterization and applications in enantioselective reactions, Tetrahedron: Asymmetry. 20 (2009) 2854-2860. doi:10.1016/j.tetasy.2009.11.012.

[188] M.K. Mishra, M. Harini, T. Kumaraguru, T. Lakshmi Prasanna, N.W. Fadnavis, A porous vessel bioreactor for gel entrapped biocatalysts: Kinetic resolution of transmethyl (4-methoxyphenyl)glycidate by Lecitase® Ultra in gelatin organogel (Gelozyme), J. Mol. Catal. B Enzym. 71 (2011) 56-62. doi:10.1016/j.molcatb.2011.03.009.

[189] G. Sheelu, G. Kavitha, N.W. Fadnavis, Efficient Immobilization of Lecitase in Gelatin Hydrogel and Degumming of Rice Bran Oil Using a Spinning Basket Reactor, J. Am. Oil Chem. Soc. 85 (2008) 739-748. doi:10.1007/s11746-008-12617.

[190] D. Yu, L. Jiang, Z. Li, J. Shi, J. Xue, Y. Kakuda, Immobilization of Phospholipase A1 and its Application in Soybean Oil Degumming, J. Am. Oil Chem. Soc. 89 (2012) 649-656. doi:10.1007/s11746-011-1943-4.

[191] J.C.S. dos Santos, N. Rueda, R. Torres, O. Barbosa, L.R.B. Gonçalves, R. Fernandez-Lafuente, Evaluation of divinylsulfone activated agarose to immobilize lipases and to tune their catalytic properties, Process Biochem. 50 (2015) 918-927. doi:10.1016/j.procbio.2015.03.018. 
1263

1264

1265

1266

1267

1268

1269

1270

1271

1272

1273

1274

1275

1276

1277

1278

1279

1280

1281

1282

1283

1284
[192] P. Zucca, R. Fernandez-Lafuente, E. Sanjust, Agarose and Its Derivatives as Supports for Enzyme Immobilization, Molecules. 21 (2016) 1577. doi:10.3390/molecules21111577.

[193] H. Zaak, L. Fernandez-Lopez, S. Velasco-Lozano, M.T. Alcaraz-Fructuoso, M. Sassi, F. Lopez-Gallego, R. Fernandez-Lafuente, Effect of high salt concentrations on the stability of immobilized lipases: Dramatic deleterious effects of phosphate anions, Process Biochem. 62 (2017) 128-134. doi:10.1016/j.procbio.2017.07.018.

[194] L. Fernandez-Lopez, R. Bartolome-Cabrero, M.D. Rodriguez, C.S. Dos Santos, N. Rueda, R. Fernandez-Lafuente, Stabilizing effects of cations on lipases depend on the immobilization protocol, RSC Adv. 5 (2015) 83868-83875. doi:10.1039/C5RA18344H.

[195] E.P. Cipolatti, M.C.C. Pinto, J. de M. Robert, T.P. da Silva, T. d. C. Beralto, J.G.F. Santos Jr, R. d. P.V. de Castro, R. Fernandez-Lafuente, E.A. Manoel, J.C.C. d. S. Pinto, D.M.G. Freire, Pilot-Scale Development of Core-Shell Polymer Supports for the Immobilization of Recombinant Lipase B from Candida antarctica and their Application in the Production of Ethyl Esters from Residual Fatty Acids, J. Appl. Polym. Sci. (2018) 10.1002/app.46727. doi:10.1002/app.46727.

[196] L. Fernandez-Lopez, N. Rueda, R. Bartolome-Cabrero, M.D. Rodriguez, T.L. Albuquerque, J.C.S. dos Santos, O. Barbosa, R. Fernandez-Lafuente, Improved immobilization and stabilization of lipase from Rhizomucor miehei on octyl-glyoxyl agarose beads by using $\mathrm{CaCl}$ 2, Process Biochem. 51 (2016) 48-52. doi:10.1016/j.procbio.2015.11.015. 
1285

1286

1287

1288

1289

1290

1291

1292

1293

1294

1295

1296

1297

1298

1299

1300

1301

1302

1303

1304

1305

1306
[197] L. Fernandez-Lopez, S.G. Pedrero, N. Lopez-Carrobles, B.C. Gorines, J.J. VirgenOrtíz, R. Fernandez-Lafuente, Effect of protein load on stability of immobilized enzymes, Enzyme Microb. Technol. 98 (2017) 18-25.

doi:10.1016/j.enzmictec.2016.12.002.

[198] H. Zaak, E.-H. Siar, J.F. Kornecki, L. Fernandez-Lopez, S.G. Pedrero, J.J. VirgenOrtíz, R. Fernandez-Lafuente, Effect of immobilization rate and enzyme crowding on enzyme stability under different conditions. The case of lipase from Thermomyces lanuginosus immobilized on octyl agarose beads, Process Biochem. 56 (2017) 117-123. doi:10.1016/j.procbio.2017.02.024.

[199] F. Silva, W. Morais Júnior, C. Silva, A. Vieira, A. Batista, A. Faria, R. Assunção, Preparation and Characterization of Cellulose Triacetate as Support for Lecitase Ultra Immobilization, Molecules. 22 (2017) 1930. doi:10.3390/molecules22111930.

[200] S. Moreno-Perez, D.F.M. Turati, J.P. Borges, P. Luna, F.J. Señorans, J.M. Guisan, G. Fernandez-Lorente, Critical Role of Different Immobilized Biocatalysts of a Given Lipase in the Selective Ethanolysis of Sardine Oil, J. Agric. Food Chem. 65 (2017) 117-122. doi:10.1021/acs.jafc.6b05243.

[201] E.A. Manoel, M. Pinto, J.C.S. dos Santos, V.G. Tacias-Pascacio, D.M.G. Freire, J.C. Pinto, R. Fernandez-Lafuente, Design of a core-shell support to improve lipase features by immobilization, RSC Adv. 6 (2016) 62814-62824. doi:10.1039/C6RA13350A.

[202] V.G. Tacias-Pascacio, S. Peirce, B. Torrestiana-Sanchez, M. Yates, A. RosalesQuintero, J.J. Virgen-Ortíz, R. Fernandez-Lafuente, Evaluation of different 
commercial hydrophobic supports for the immobilization of lipases: tuning their stability, activity and specificity, RSC Adv. 6 (2016) 100281-100294. doi:10.1039/C6RA21730C.

[203] V.G. Tacias-Pascacio, J.J. Virgen-Ortíz, M. Jiménez-Pérez, M. Yates, B. Torrestiana-Sanchez, A. Rosales-Quintero, R. Fernandez-Lafuente, Evaluation of different lipase biocatalysts in the production of biodiesel from used cooking oil: Critical role of the immobilization support, Fuel. 200 (2017) 1-10. doi:10.1016/j.fuel.2017.03.054.

[204] V.G. Tacias-Pascacio, B. Torrestiana-Sánchez, L. Dal Magro, J.J. Virgen-Ortíz, F.J. Suárez-Ruíz, R.C. Rodrigues, R. Fernandez-Lafuente, Comparison of acid, basic and enzymatic catalysis on the production of biodiesel after RSM optimization, Renew. Energy. 135 (2019) 1-9. doi:10.1016/j.renene.2018.11.107.

[205] J.S. Alves, C. Garcia-Galan, D. Danelli, N. Paludo, O. Barbosa, R.C. Rodrigues, R. Fernandez-Lafuente, Use of Lecitase-Ultra immobilized on styrene-divinylbenzene beads as catalyst of esterification reactions: Effects of ultrasounds, Catal. Today. 255 (2015) 27-32. doi:10.1016/j.cattod.2014.11.036.

[206] C. Garcia-Galan, O. Barbosa, K. Hernandez, J.C.S. Santos, R.C. Rodrigues, R. Fernandez-Lafuente, Evaluation of Styrene-Divinylbenzene Beads as a Support to Immobilize Lipases, Molecules. 19 (2014) 7629-7645. doi:10.3390/molecules19067629.

[207] N. Liu, M. Fu, Y. Wang, Q. Zhao, W. Sun, M. Zhao, Immobilization of lecitase® ultra onto a novel polystyrene DA-201 resin: Characterization and biochemical 
properties, Appl. Biochem. Biotechnol. 168 (2012) 1108-1120. doi:10.1007/s12010012-9845-y.

[208] N. Liu, Y. Wang, Q. Zhao, C. Cui, M. Fu, M. Zhao, Immobilisation of lecitase® ultra for production of diacylglycerols by glycerolysis of soybean oil, Food Chem. 134 (2012) 301-307. doi:10.1016/j.foodchem.2012.02.145.

[209] N. Rueda, J.C.S. dos Santos, R. Torres, C. Ortiz, O. Barbosa, R. FernandezLafuente, Improved performance of lipases immobilized on heterofunctional octylglyoxyl agarose beads, RSC Adv. 5 (2015) 11212-11222. doi:10.1039/C4RA13338B.

[210] J.J. Virgen-Ortíz, V.G. Tacias-Pascacio, D.B. Hirata, B. Torrestiana-Sanchez, A. Rosales-Quintero, R. Fernandez-Lafuente, Relevance of substrates and products on the desorption of lipases physically adsorbed on hydrophobic supports, Enzyme Microb. Technol. 96 (2017) 30-35. doi:10.1016/j.enzmictec.2016.09.010.

[211] D.B. Hirata, T.L. Albuquerque, N. Rueda, J.J. Virgen-Ortíz, V.G. Tacias-Pascacio, R. Fernandez-Lafuente, Evaluation of different immobilized lipases in transesterification reactions using tributyrin: Advantages of the heterofunctional octyl agarose beads, J. Mol. Catal. B Enzym. 133 (2016) 117-123. doi:10.1016/j.molcatb.2016.08.008.

[212] N. Rueda, C.S. dos Santos, M.D. Rodriguez, T.L. Albuquerque, O. Barbosa, R. Torres, C. Ortiz, R. Fernandez-Lafuente, Reversible immobilization of lipases on octyl-glutamic agarose beads: A mixed adsorption that reinforces enzyme immobilization, J. Mol. Catal. B Enzym. 128 (2016) 10-18. 
doi:10.1016/j.molcatb.2016.03.002.

1352

1353

1354

1355

1356

1357

1358

1359

1360

1361

1362

1363

1364

1365

1366

1367

1368

1369

1370

1371

1372

[213] N. Rueda, T. Albuquerque, R. Bartolome-Cabrero, L. Fernandez-Lopez, R. Torres, C. Ortiz, J. dos Santos, O. Barbosa, R. Fernandez-Lafuente, Reversible Immobilization of Lipases on Heterofunctional Octyl-Amino Agarose Beads Prevents Enzyme Desorption, Molecules. 21 (2016) 646. doi:10.3390/molecules21050646.

[214] G. Fernandez-Lorente, J.M. Palomo, J.M. Guisan, R. Fernandez-Lafuente, Effect of the immobilization protocol in the activity, stability, and enantioslectivity of Lecitase ${ }^{\circledR}$ Ultra, J. Mol. Catal. B Enzym. 47 (2007) 99-104. doi:10.1016/j.molcatb.2007.04.008.

[215] Z. Cabrera, G. Fernandez-Lorente, J.M. Palomo, J.M. Guisan, R. FernandezLafuente, Asymmetric hydrolysis of dimethyl 3-phenylglutarate catalyzed by Lecitase Ultra®. Effect of the immobilization protocol on its catalytic properties, Enzyme Microb. Technol. 43 (2008) 531-536. doi:10.1016/j.enzmictec.2008.07.001.

[216] G. Fernandez-Lorente, M. Filice, M. Terreni, J.M. Guisan, R. Fernandez-Lafuente, J.M. Palomo, Lecitase ${ }^{\circledR}$ ultra as regioselective biocatalyst in the hydrolysis of fully protected carbohydrates. Strong modulation by using different immobilization protocols, J. Mol. Catal. B Enzym. 51 (2008) 110-117. doi:10.1016/j.molcatb.2007.11.017.

[217] R.C. Rodrigues, O. Barbosa, C. Ortiz, Á. Berenguer-Murcia, R. Torres, R. Fernandez-Lafuente, Amination of enzymes to improve biocatalyst performance: coupling genetic modification and physicochemical tools, RSC Adv. 4 (2014) 
1374

1375

1376

1377

1378

1379

1380

1381

1382

1383

1384

1385

1386

1387

1388

1389

1390

1391

1392

1393
[218] C. Garcia-Galan, J.C.S. dos Santos, O. Barbosa, R. Torres, E.B. Pereira, V.C. Corberan, L.R.B. Gonçalves, R. Fernandez-Lafuente, Tuning of Lecitase features via solid-phase chemical modification: Effect of the immobilization protocol, Process Biochem. 49 (2014) 604-616. doi:http://dx.doi.org/10.1016/j.procbio.2014.01.028.

[219] J.C.S. dos Santos, C. Garcia-Galan, R.C. Rodrigues, H.B. de Sant' Ana, L.R.B. Gonçalves, R. Fernandez-Lafuente, Improving the catalytic properties of immobilized Lecitase via physical coating with ionic polymers, Enzyme Microb. Technol. 60 (2014) 1-8. doi:10.1016/j.enzmictec.2014.03.001.

[220] J.C.S. dos Santos, C. Garcia-Galan, R.C. Rodrigues, H.B. de Sant'Ana, L.R.B. Gonçalves, R. Fernandez-Lafuente, Stabilizing hyperactivated lecitase structures through physical treatment with ionic polymers, Process Biochem. 49 (2014) 15111515. doi:10.1016/j.procbio.2014.05.009.

[221] F. Kazenwadel, M. Franzreb, B.E. Rapp, Synthetic enzyme supercomplexes: coimmobilization of enzyme cascades, Anal. Methods. 7 (2015) 4030-4037. doi:10.1039/C5AY00453E.

[222] S. Velasco-Lozano, F. López-Gallego, Wiring step-wise reactions with immobilized multi-enzyme systems, Biocatal. Biotransformation. 36 (2018) 184-194. doi:10.1080/10242422.2017.1310208.

[223] C. Schmid-Dannert, F. López-Gallego, Advances and opportunities for the design of self-sufficient and spatially organized cell-free biocatalytic systems, Curr. Opin. 
Chem. Biol. 49 (2019) 97-104. doi:10.1016/j.cbpa.2018.11.021.

1395

1396

1397

1398

1399

1400

1401

1402

1403

1404

1405

1406

1407

1408

1409

1410

1411

1412

1413

[224] S. Peirce, J.J. Virgen-Ortíz, V.G. Tacias-Pascacio, N. Rueda, R. Bartolome-Cabrero, L. Fernandez-Lopez, M.E. Russo, A. Marzocchella, R. Fernandez-Lafuente, Development of simple protocols to solve the problems of enzyme coimmobilization. Application to coimmobilize a lipase and a $\beta$-galactosidase, RSC Adv. 6 (2016) 61707-61715. doi:10.1039/C6RA10906C.

[225] J.J. Virgen-Ortíz, S. Peirce, V.G. Tacias-Pascacio, V. Cortes-Corberan, A. Marzocchella, M.E. Russo, R. Fernandez-Lafuente, Reuse of anion exchangers as supports for enzyme immobilization: Reinforcement of the enzyme-support multiinteraction after enzyme inactivation, Process Biochem. 51 (2016) 1391-1396. doi:10.1016/j.procbio.2016.06.020.

[226] H. Zaak, J.F. Kornecki, E.-H. Siar, L. Fernandez-Lopez, V.C. Corberán, M. Sassi, R. Fernandez-Lafuente, Coimmobilization of enzymes in bilayers using pei as a glue to reuse the most stable enzyme: Preventing pei release during inactivated enzyme desorption, Process Biochem. 61 (2017) 95-101. doi:10.1016/j.procbio.2017.06.014.

[227] H. Zaak, L. Fernandez-Lopez, C. Otero, M. Sassi, R. Fernandez-Lafuente, Improved stability of immobilized lipases via modification with polyethylenimine and glutaraldehyde, Enzyme Microb. Technol. 106 (2017) 67-74. doi:10.1016/j.enzmictec.2017.07.001. 


\section{Figure Legends}

\section{Figure 1. Conformational equilibrium and interfacial activation of lipases.}

Figure 2. Generic phospholipid structure and cleavage site of the different phospholipases enzymes. Phospholipase A1 (PLA1) and phospholipase A2 (PLA2) cleave the acyl ester bonds at $s n-1$ and $s n-2$, respectively. Phospholipase B (PLB) can be deacylated at both $s n-1$ and $s n-2$ positions. Phospholipase C (PLC) catalyzes the hydrolysis of the ester bond from the sn-3 (3). Phospholipase D (PLD) removes the head group. R1 and R2 correspond to nonpolar fatty acids. The black arrows for phospholipases (PLA1, PLA2, PLB, PLC, and PLD) indicate their site of hydrolysis. The structure was drawn using the molecular graphics program JSmol.

Figure 3. Bio-imprinting of the open form of Lecitase Ultra induced by detergents after coating with PEI.

Figure 4- Co-immobilization of $\beta$-galactosidase and Lecitase Ultra. Lecitase Ultra was immobilized on octyl agarose via interfacial activation, coated with PEI and modified with glutaraldehyde to have covalent bonds between enzyme and support. After reduction of the composite, galactosidase was immobilized via ion exchange. PEI will remain immobilized on the support at any ionic strength. 